Hugo Eduardo Carvajal Oviedo (c) PhD. ${ }^{1}$

Gladys Betty Chambi Cahuana. ${ }^{2}$

Erika Sakuma Calatayud. ${ }^{3}$

Paola Mariana Cáceres Gonzales. ${ }^{4}$

Marisabel Tiñini Rufino. ${ }^{5}$

Correspondencia a:

${ }^{1}$ Médico - Cirujano

Doctorante en neurociencias clínicas y experimentales

Master en medicina forense Especialista en auditoria médica.

${ }^{2}$ Médico- Cirujano

Magister en medicina forense

Especialidad en salud pública- Gerencia en salud

Medico centro de salud integral Tembladerani - La Paz.

${ }^{3}$ Médico - Cirujano

Master en medicina forense Médico forense en el IDIF Tarija.

${ }^{4}$ Médico - Cirujano

Master en medicina forense Docente de medicina legal.

${ }^{5}$ Médico- Cirujano

Diplomado en ciencias forenses

Cursante de la Maestría forense.

carvajaloviedo@gmail.com gbsam_chambi@hotmail. com

sakumaerika@hotmail.com paola.m.caceres.gonzales@gmail.com

Marisabeltr12335@gmai. com

Procedencia y arbitraje: No comisionado, sometido a arbitraje externo

Recibido para publicación: 2 de junio de 2018 Aceptado para publicación: 04 de agosto de 2018

Citar como:

$\mathrm{Re} \mathrm{Ci} \mathrm{Sa}$ UNI

2018;5(2):28-63

\section{POSICIÓN DEL CUERPO DE LA VÍCTIMA EN EL LUGAR DE LOS HECHOS}

\author{
VICTIMS BODY POSITION AT THE SCENE OF THE INCI- \\ DENT
}

POSIÇÃO DO CORPO DA VÍTIMA NO LUGAR DOS FATOS

\section{Resumen.}

Los cuerpos sin vida adoptan siempre una posición final con la que son encontrados en el lugar de los hechos.

En este artículo se describen las distintas posiciones cadavéricas, para especificar el tipo de posición cadavérica se toma como base el plano horizontal del cuerpo, denominándose decúbito, entre las posiciones cadavéricas tenemos: decúbito dorsal, decúbito ventral o prono, decúbito lateral derecho, decúbito lateral izquierdo, posición en rana, posición geno/cubital, posición geno/pectoral, posición sedente, la suspensión completa, suspensión completa invertida, suspensión incompleta, sumersión completa, sumersión incompleta, posición de roser o proetz, posición de boxeador, posición tónico- cervical asimétrico, posición fetal, posición de depage.

Según la posición de las extremidades, tenemos brazos en extensión, brazos en aducción, brazos en flexión, piernas en extensión, piernas en abducción, piernas en flexión y extremidades en rotación.

Las posiciones en la que un cadáver se puede encontrar por motivo de la posible comisión de un hecho delictuoso nos ayudan a determinar la probable dinámica de la muerte, ya que las posiciones cadavéricas son proclives a diferentes tipos de hechos como ser un homicidio, suicidio o que el sujeto haya sufrido un accidente ya sea por descuido o provocado por algún tercero.

La posición del cadáver también es importante para determinar si el cadáver fue movido de posición y/o lugar, por lo cual el médico forense debería participar en el levantamiento del cadáver.

Palabras clave: Posiciones cadavéricas, homicidio, suicidio, accidental.

\section{Abstract.}

Bodies always adopt final positions or posture at the time of death, at the final place called scene of death where the dead body is found.

This article describes the different cadaverous positions taking the lying down posture denominated decubitus kind as the base of specifics. Among types of cadaverous positions we have: Dorsal decubitus, ventral or prone decubitus, straight lateral decubitus, left lateral decubitus, frog position, genus cubital posi- 
tion, genus pectoral position, sitting position, complete suspension, complete inverted suspension, incomplete suspension, complete submersion, incomplete submersion, position of roser or proetz, boxer position, asymmetric cervical tonic position, fetal position, depage position.

Considering the limbs position we have: arms extension, arms in abduction, arms in flexion, legs in extension, legs in abduction, legs in flexion and limb rotation position. In case of murder event, dead body positions help us to determine the probable homicide dynamic, the cadaverous positions give us hints of different trends of the occurrence of the crime, as well as homicide, suicide or the related events when the individual had already suffered an accident by careless or produced by someone.

The body posture at the scene of death is also important to determine if the body was moved of position or from place and the correct forensic interpretations, therefore forensic medic should take part in the removal of the body.

Key words: Cadaveric positions, homicide, suicide, accidental.

\section{RESUMO.}

Os corpos sem vida sempre adotam uma posição final com a qual se encontram no lugar dos acontecimentos.

Neste artigo várias posições de cadáveres descrito, para especificar o tipo de posição de cadáver é tomada com base no plano horizontal do corpo, denominando decúbito entre as posições de cadáveres são: supina posição, ou propenso, a posição lateral direito, decúbito lateral esquerda, a posição rã geno / posição ulnar geno / posição peitoral, posição, a suspensão completa, a suspensão invertida completa, a suspensão incompleta, submersão completa, submersão incompleta, ou posição Proetz Roser, pugilista posição sentada, posição tónico cervical assimétrica, posição fetal, posição de depação.

Dependendo da posição dos membros, braços têm braços de extensão aduzidos, braços flexionados, pés estendidos, pernas raptadas, flexionou as pernas e os membros em rotação.

As posições em que um cadáver pode ser encontrada por causa da possível prática de um ato criminoso nos ajuda a determinar a dinâmica provável da morte, como as posições cadavéricos são propensas a diferentes tipos de eventos, tais como homicídio, suicídio ou que o sujeito sofreu um acidente devido a negligência ou causado por terceiros.

A posição do corpo é também importante para determinar se o corpo foi movido a partir da posição e / ou lugar, de modo que o investigador deveria participar no cadáver.

Palavras-chave: posições de cadáver, homicídio, suicídio, acidental.

\section{INTRODUCCIÓN}

Es un acto médico legal que constituye la primera etapa en el proceso de autopsia. Se le conoce también como levantamiento del cadáver, investigación en la escena del suceso, descripción del lugar del crimen, descripción del ambiente y observaciones sobre el lugar del suceso entre otros y puede definirse como "el estudio multidisciplinario, cuidadoso y documentado del cadáver y del lugar donde se produjo la muerte o donde se ha hallado el cadáver. 
En el procesamiento del lugar del hecho es importante que los profesionales que intervengan sean profesionales capacitados adecuadamente, primero en la fijación y colección de indicios a partir de la escena del crimen que puede conducir a la resolución de un determinado delito y en la descripción y fijación adecuada de la posición cadavérica en la escena del hecho, debido a que este procesamiento en único he irreproducible, por el contrario, una mala actuación puede impedir que la investigación forense contribuya al esclarecimiento de los hechos.

Para el abordaje de la escena de la muerte existen varios métodos o planes de manejo posibles, todos descritos con la finalidad de proteger la escena al tiempo que se recolectan pruebas estableciendo las relaciones de distancia con respecto al occiso.

En nuestro país se tiene aún la deficiencia de contar con los suficientes médicos forenses para realizar el levantamiento del cadáver, el mismo que varias oportunidades, generalmente en áreas rurales, hace un médico general o el personal policial, motivo por el cual es de importancia tener el conocimiento básico de las posiciones cadavéricas para un adecuado procesamiento en el lugar del hecho y de esta forma orientar al perito que realizará la autopsia.

\section{FUNDAMENTO JURÍDICO Y CRIMINALÍSTICO}

Si bien en nuestro código de Procedimiento Penal de Bolivia en su Art. 177 "(Levantamiento e identificación de cadáveres) La policía realizara la inspección corporal preliminar y la descripción de la situación o posición del cuerpo y la naturaleza de las lesiones o heridas conforme a lo previsto en el art. 174 de este Código. (...) Procederá a levantar el cadáver, disponiendo su traslado a los gabinetes médico forenses o al lugar en el que se practicará la autopsia, a su identificación final y la entrega a sus familiares".

Este código si bien no incluye al médico forense como sujeto que deba necesariamente participar en el levantamiento de cadáveres, es de importancia su participación en este acto investigativo a realizarse en la escena junto con el equipo multidisciplinario, debido que cada participante tiene importancia en el momento del procesamiento de la escena del hecho.

En las investigaciones de muertes violentas que involucra a la criminalística; los cuerpos sin vida siempre adoptarán una posición final después de la muerte, esta posición cadavérica, en el lugar de los hechos, nos ayuda a en la orientación de la investigación, pudiendo dar luces si es una escena es primaria, secundaria o de otra índole, de acuerdo la posición del cuerpo y a los indicios adyacentes. ${ }^{1 .}$

Es de importancia para la investigación criminalística que el forense revise la posición del o los cadáveres en el lugar del hecho, esto para conocer mejor su posible dinámica de muerte y, consecuentemente, permita tener una pista que enfoque, aun de forma preliminar, la investigación.

Los funcionarios policiales que acudan deben evitar mover el cadáver de su posición original, exceptuando cuando existan justificadas razones que entorpezcan el trabajo, (por ejemplo: peligro inminente para otra persona, obstáculo para realizar alguna tarea pericial impostergable, posibilidad de ocurrencia de alguna catástrofe).

De acuerdo a normas de criminalística, se procederá, en compañía con el médico forense, a examinar el cadáver en el lugar de los hechos, teniendo en cuenta los si- 
guientes aspectos:

- Edad.

- Sexo.

- Actitud.

- Posición del cuerpo.

- Descripción física del cuerpo.

- Descripción de la vestimenta.

- Estado del cuerpo, con especial atención en las heridas y las amputaciones que pueda presentar, con especificación de la data estimada de la muerte, etcétera.

- Lesiones que presenta el cuerpo.

- Los indicios o las evidencias que se encuentren sobre el cuerpo o en su perímetro inmediato y corran el riesgo de desaparecer o deteriorarse cuando sea movido el cadáver o trasladado a la morgue, deberán tener prioridad de levantamiento.

- Se preservarán las manos con bolsas de papel y si bien en caso de riesgo de pérdida de algún indicio o evidencia se procederá a recogerlo en el lugar de los hechos.

- Realizar la toma fotográfica que permitan observar, desde diferentes ángulos, la posición del cadáver, así como los indicios que se encuentren en su perímetro inmediato.

\section{POSICIONES DE CADÁVERES}

La actitud se relaciona a tener en cuenta cómo se encontró al cadáver (con una cuerda alrededor del cuello, con mordaza, con ataduras, la distancia a que se hallaba el arma empleada con relación al cadáver, arma en la mano, etc.).

La posición se refiere a: cómo tiene el cadáver cada uno de sus segmentos corporales (cabeza tronco, extremidades superiores e inferiores) respecto al sitio (cama, silla, sillón, mesa) sobre el cual fue hallado (decúbito dorsal, ventral, lateral, geno/pectoral, etc.), y respecto a sí mismo (flexión, extensión, etc.).

\section{DECÚBITO DORSAL O SUPINO}

Esta posición es cuando el cuerpo tiene su apoyo en regiones posteriores sobre el plano de soporte, con la cara mirando al cielo, aunque pueden existir posiciones en que la cabeza se encuentra rotada a la derecha o a la izquierda, y los miembros superiores e inferiores pueden estar orientados hacia determinado punto. Pero siempre la espalda sobre el piso. ${ }^{2}$. (ver figura Nro. 1 y 2 )

\section{DECÚBITO VENTRAL O PRONO}

En esta posición el cuerpo se encuentra sobre las regiones anteriores del cuerpo en el plano de soporte, con la cara mirando al piso, aunque puede haber rotación cefálica a la derecha o a la izquierda y de igual modo los miembros superiores e inferiores pueden estar orientados hacia determinado punto. ${ }^{3 .}$ (ver figura Nro. 3 y 4 )

\section{DECÚBITO LATERAL DERECHO}

Esta posición es cuando el cuerpo descansa sobre la región lateral derecha en el plano de soporte, por lo general con la región facial derecha apoyada en el plano, los miembros superiores e inferiores se orientan a determinado punto, sea extendidos o flexionados 4. (ver figura Nro. 5) 


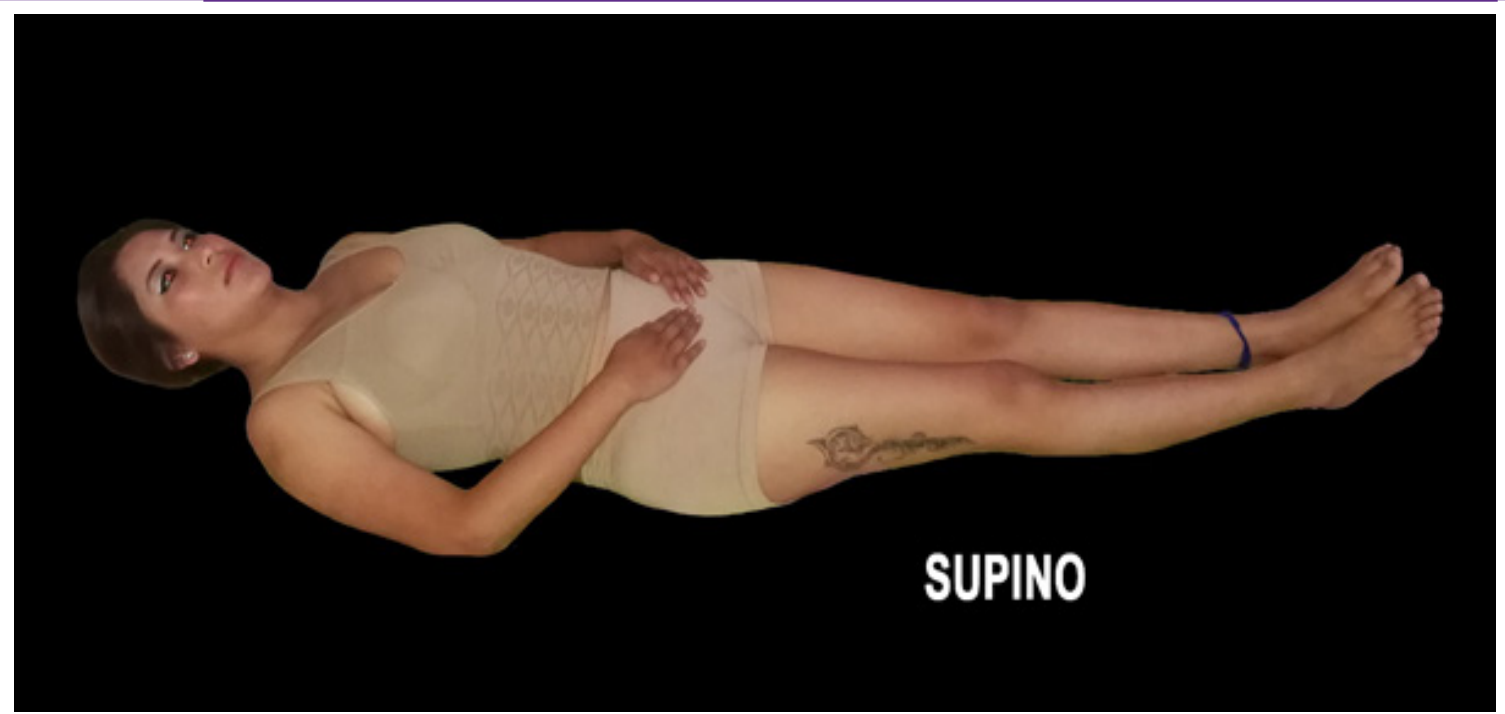

Figura Nro. 1

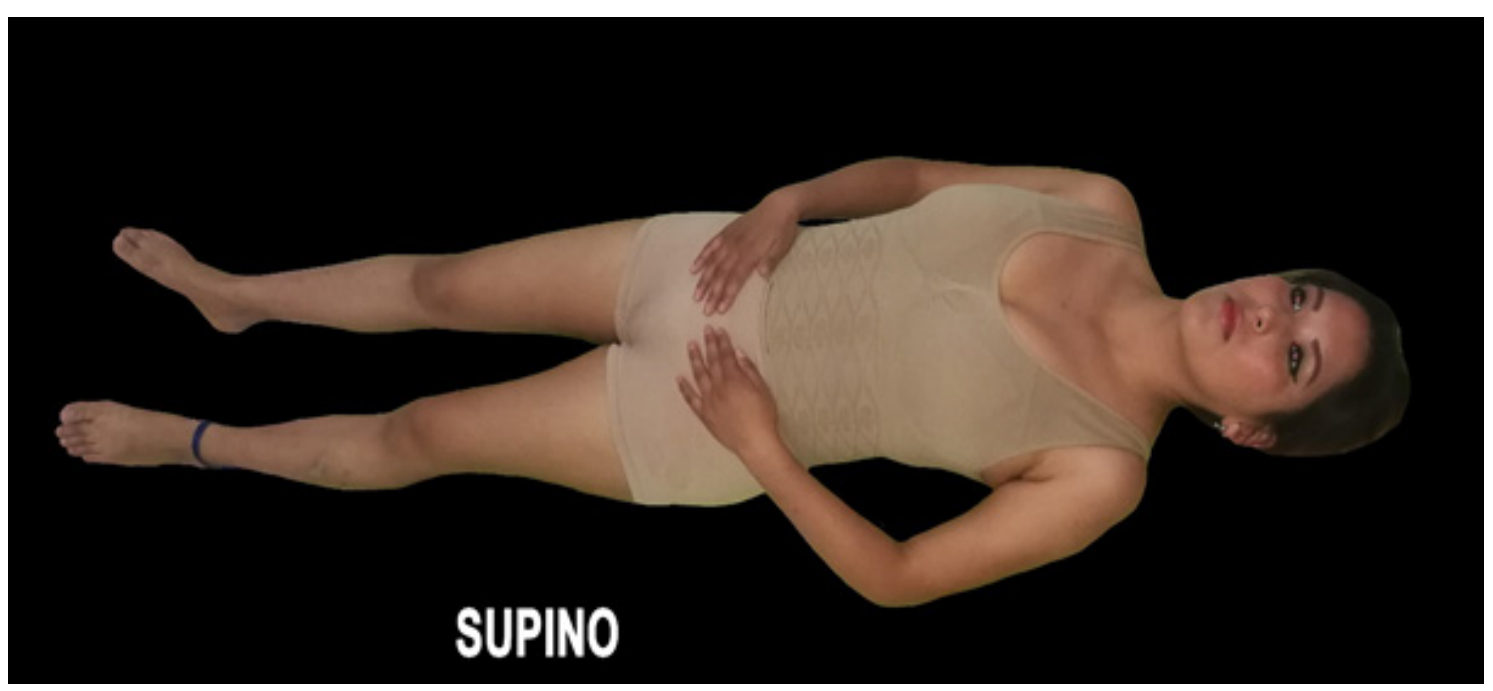

Figura Nro. 2

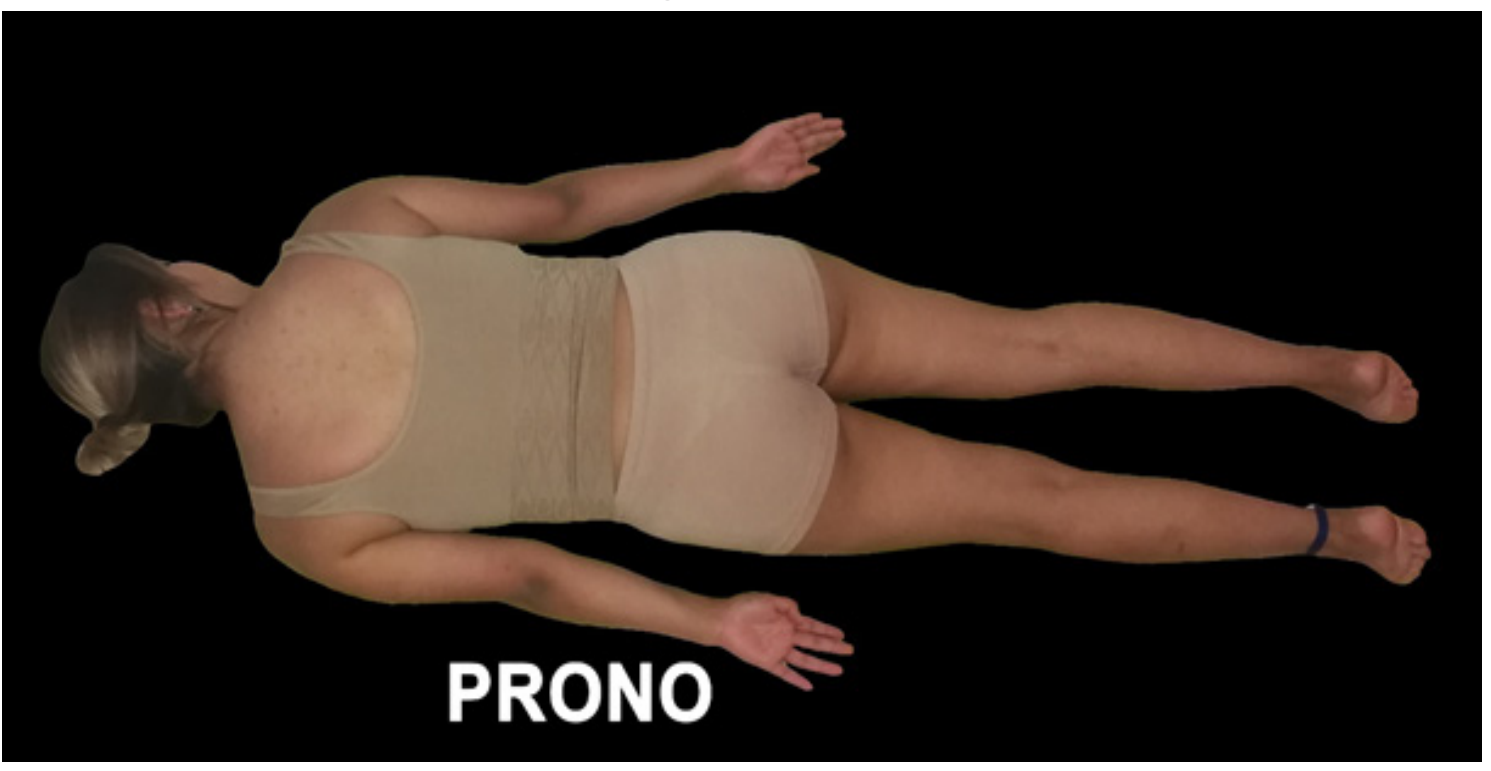

Figura Nro. 3 


\section{Revista Científica de Salud UNITEPC}

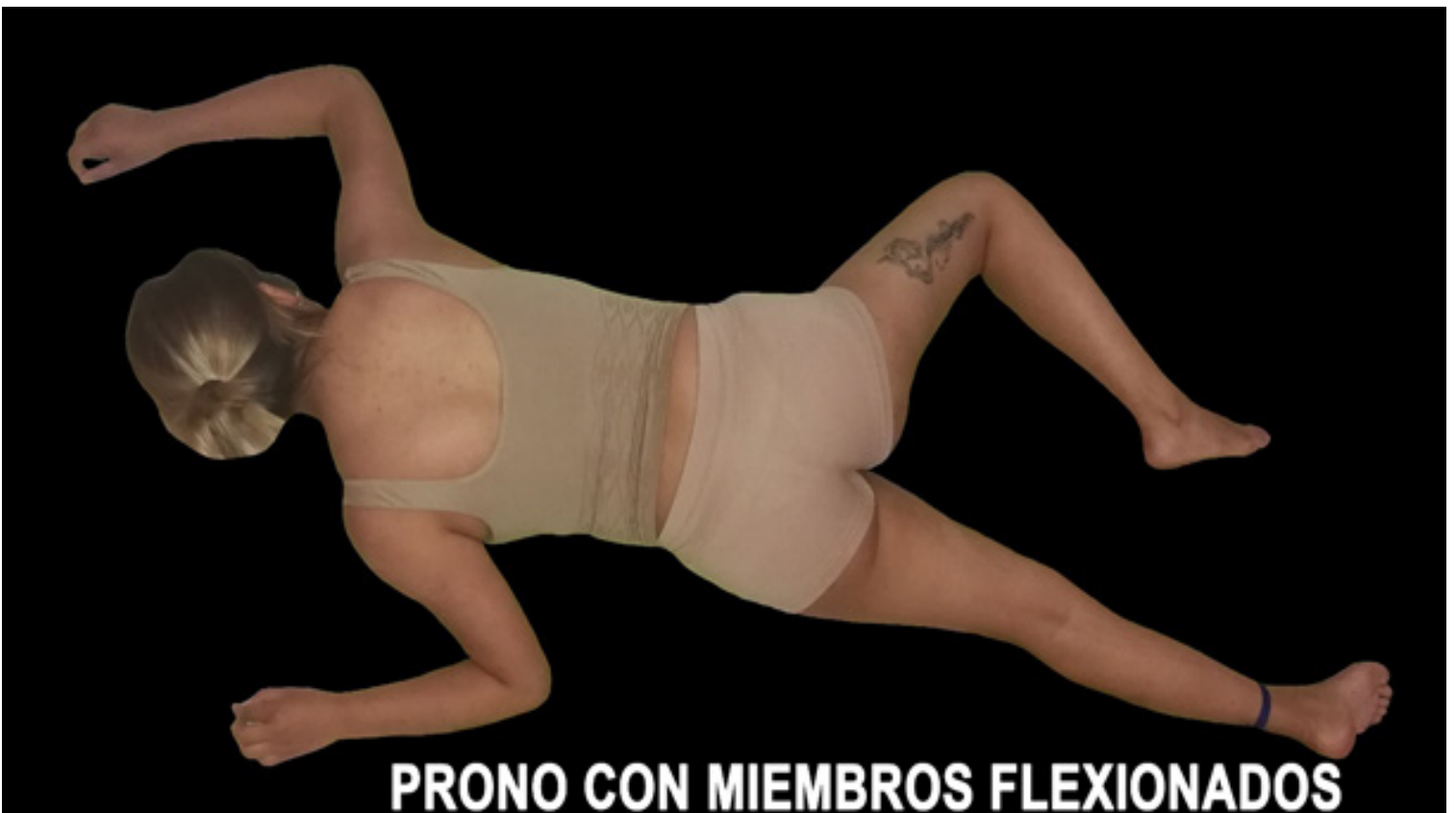

Figura Nro. 4

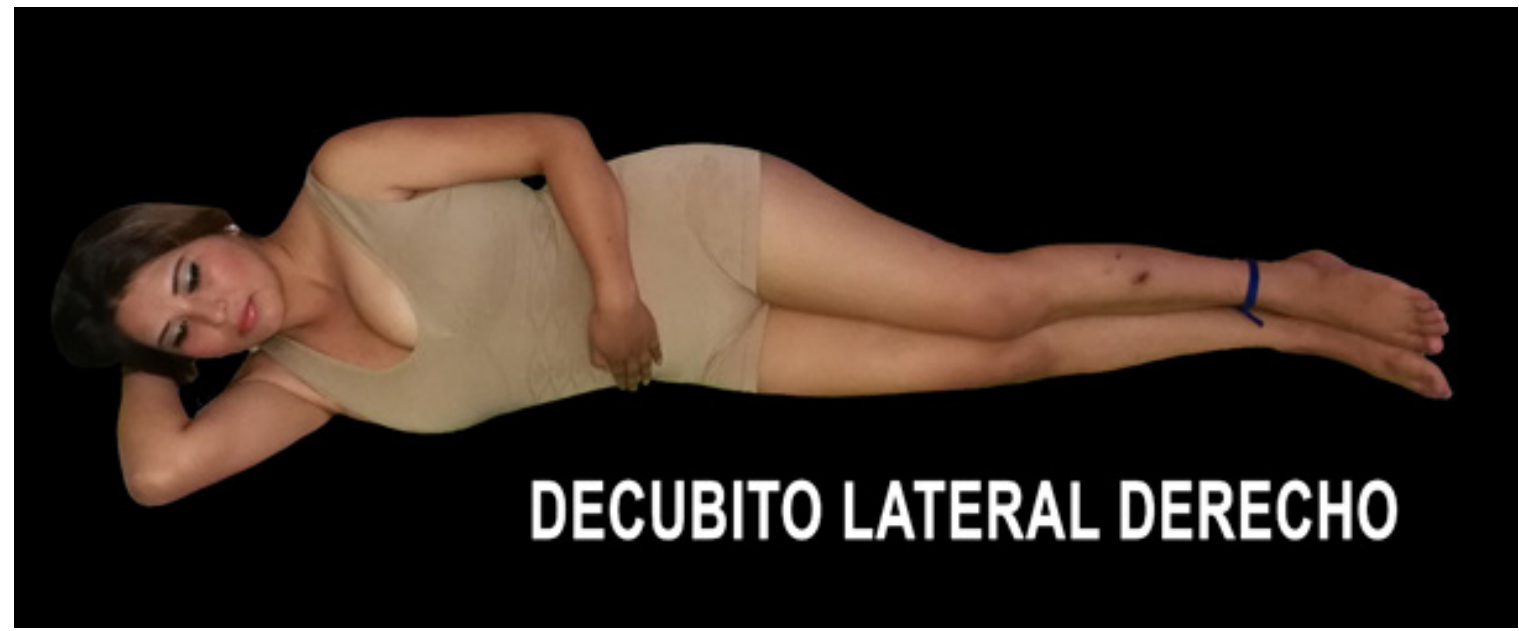

Figura Nro.5

\section{DECÚBITO LATERAL IZQUIERDO}

Esta posición es cuando el cuerpo descansa sobre la región lateral izquierda del cuerpo sobre el plano soporte, por lo general con la cara hacia el mismo lado y los miembros superiores e inferiores orientados hacia determinado punto, ya sean extendidos o flexionados. ${ }^{5 .}$ (ver figura Nro.6)

\section{POSICIÓN EN RANA}

Esta posición es cuando el cadáver se encuentra en decúbito dorsal, y las piernas en flexión, casi unidos los talones, puede existir alguna variante como un miembro en extensión. Dejando al descubierto la región genital en el caso de violación es común que el cadáver presente esta posición (ver figura Nro.7 y 8).

\section{POSICIÓN GENO/CUBITAL O MAHOMETANA}

Esta posición consiste en que el cadáver se encuentra de rodillas con ambos brazos 


\section{Revista Científica de Salud UNITEPC}

ISSN 2520 - 9825

bajo el tórax, codos apoyados en un plano. ${ }^{16}$. (ver figura Nro.9 y 10).

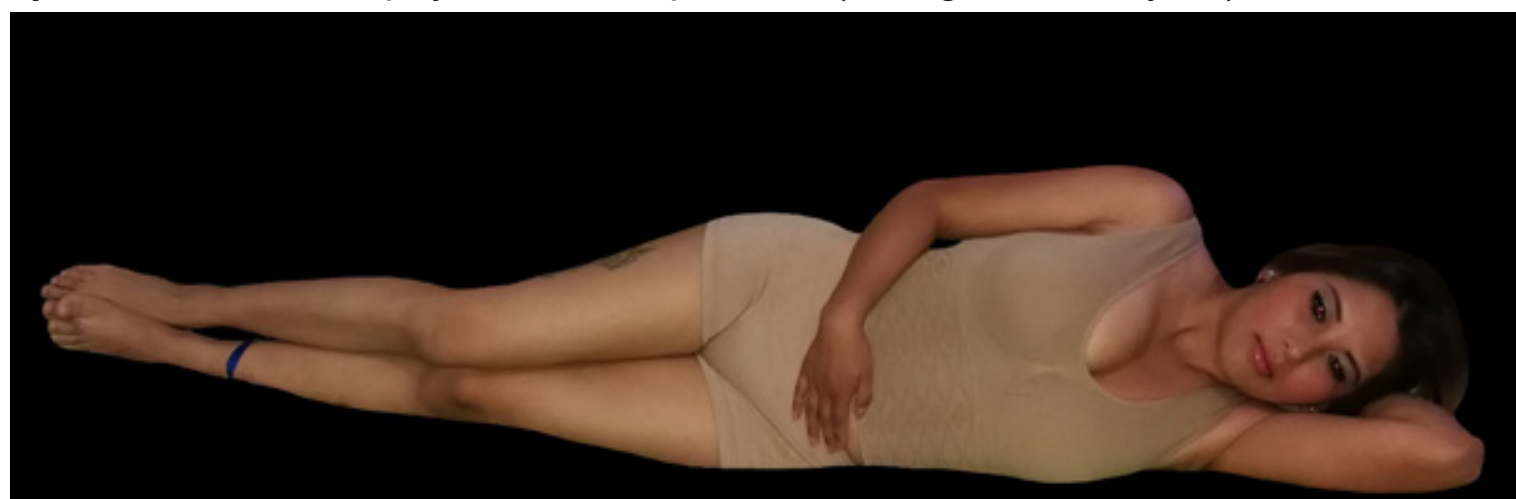

DECUBITO LATERAL IZQUIERDO

Figura Nro. 6

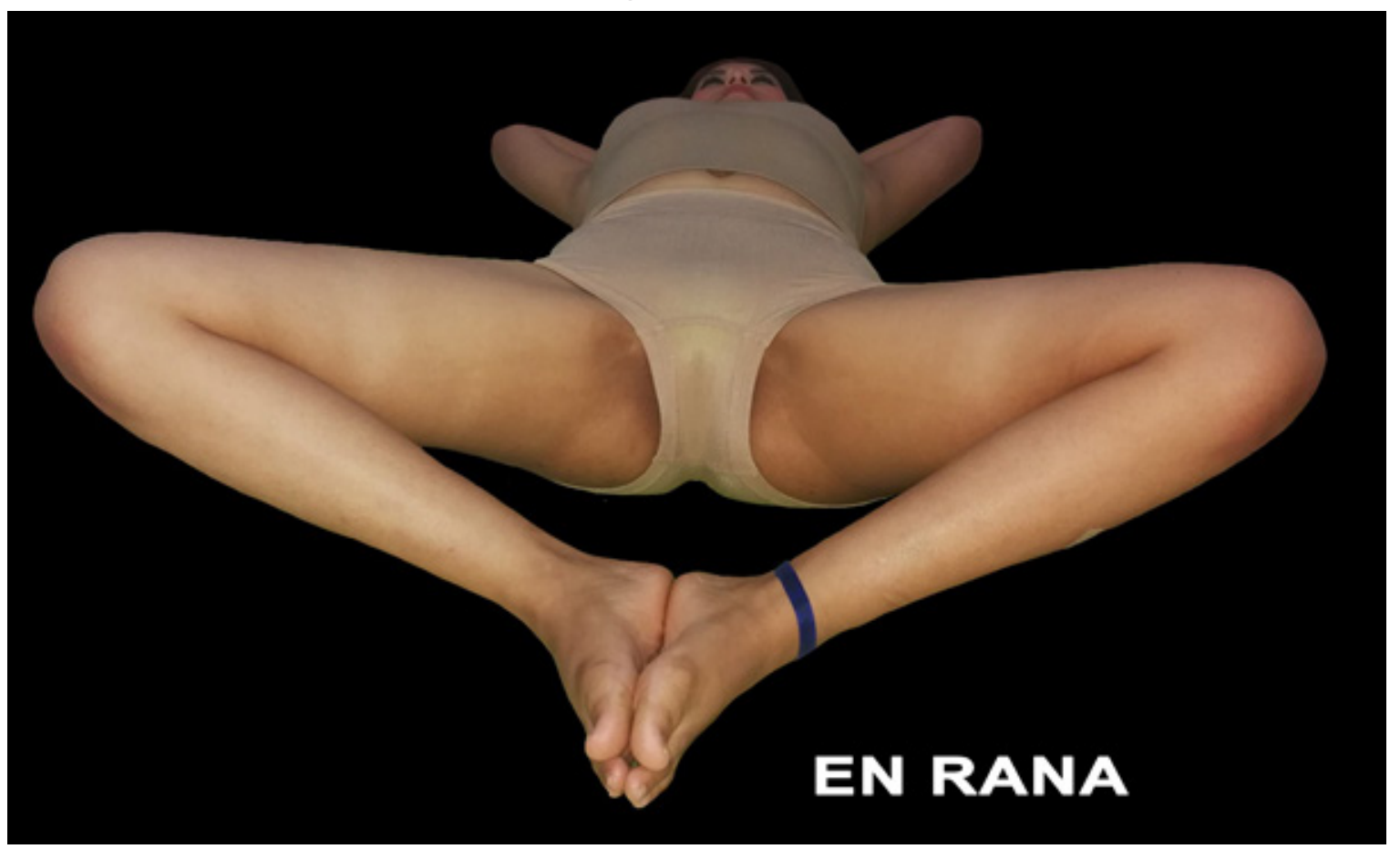

Figura Nro. 7

\section{POSICIÓN GENO/PECTORAL}

En esta posición el cadáver se encuentra apoyado sobre las rodillas y el tórax, es decir el cuerpo se mantiene empinado, con ambos brazos en extensión. La cabeza puede quedar con rotación a la derecha o a la izquierda y los miembros superiores en extensión pueden estar colocados en cualquier orientación. Es muy común con las manos atadas y en violaciones ${ }^{16}$. (ver figura Nro.11)

\section{POSICIÓN SEDENTE}

En esta posición el cuerpo se encuentra sentado pudiendo ser con el tórax en forma vertical o inclina hacia delante, o puede encontrarse con el tórax flexionado a la derecha o a la izquierda, teniéndose la cabeza igualmente inclinada hacia delante o hacia atrás. Esta posición se puede encontrar en el piso, en una silla, banca, cama, 
etcétera, y los miembros superiores pueden encontrarse extendidos o flexionados 6 . (ver figura Nro.12, 13y 14).

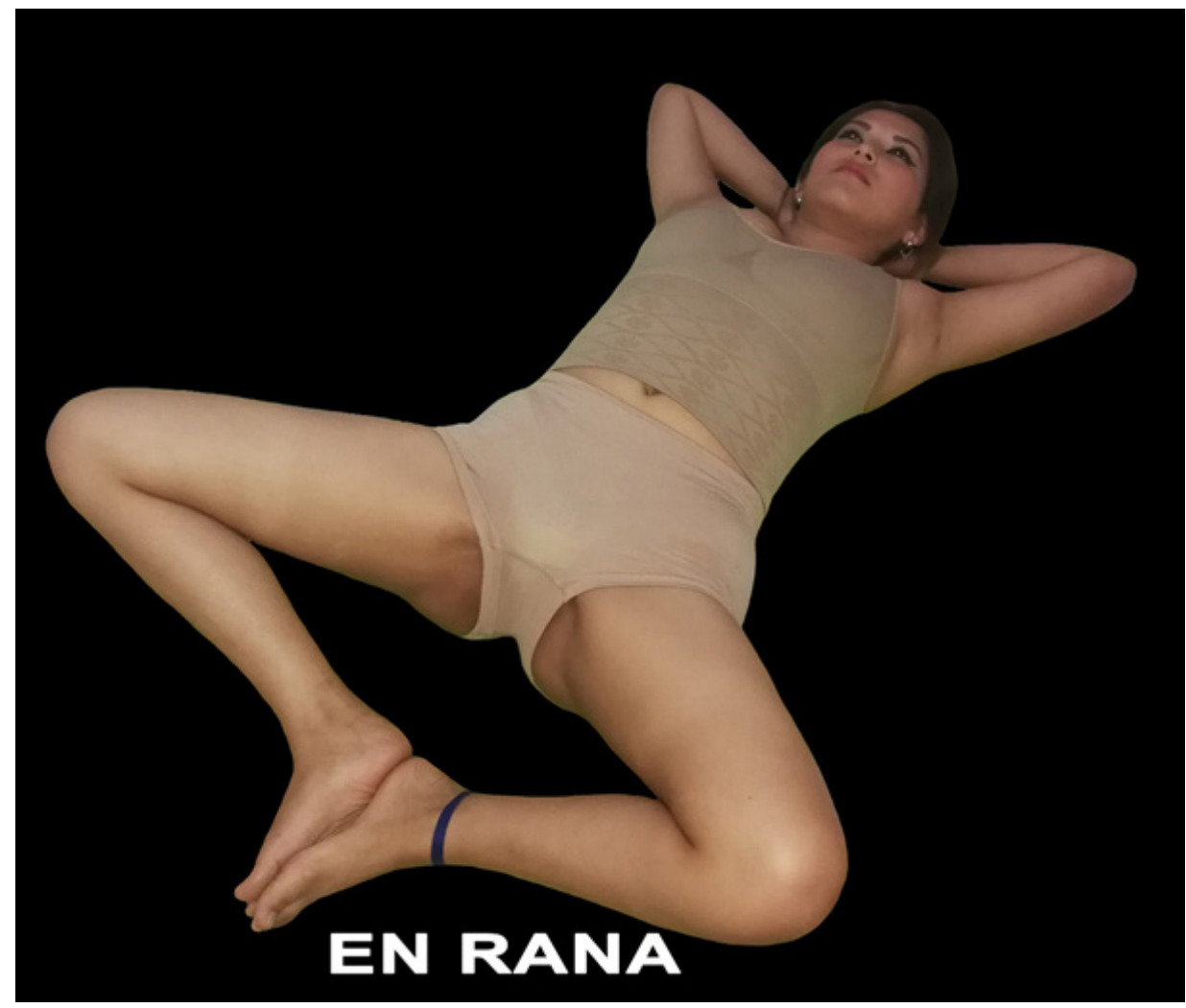

Figura Nro. 8

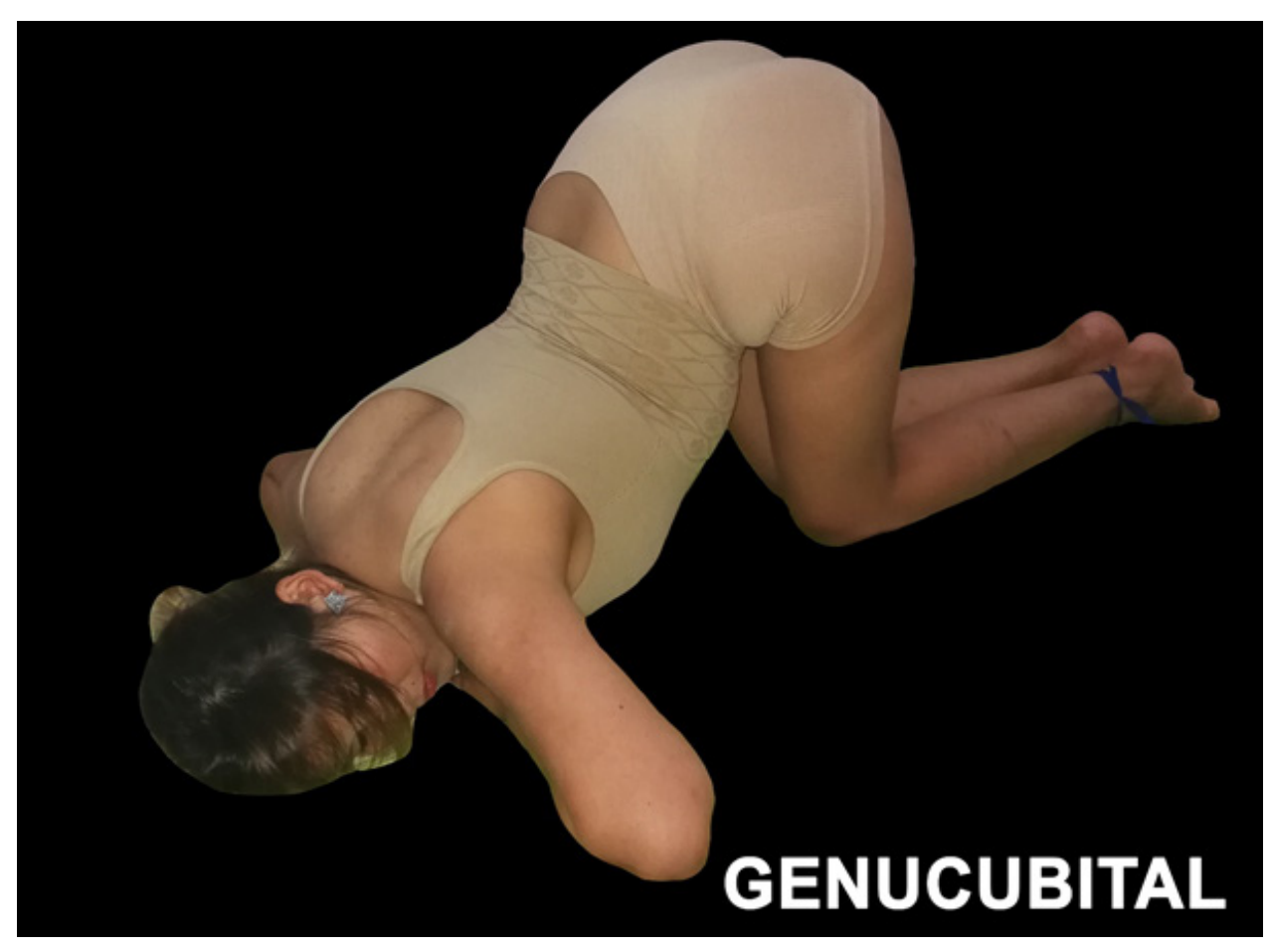

Figura Nro. 9 
Revista Científica de Salud UNITEPC

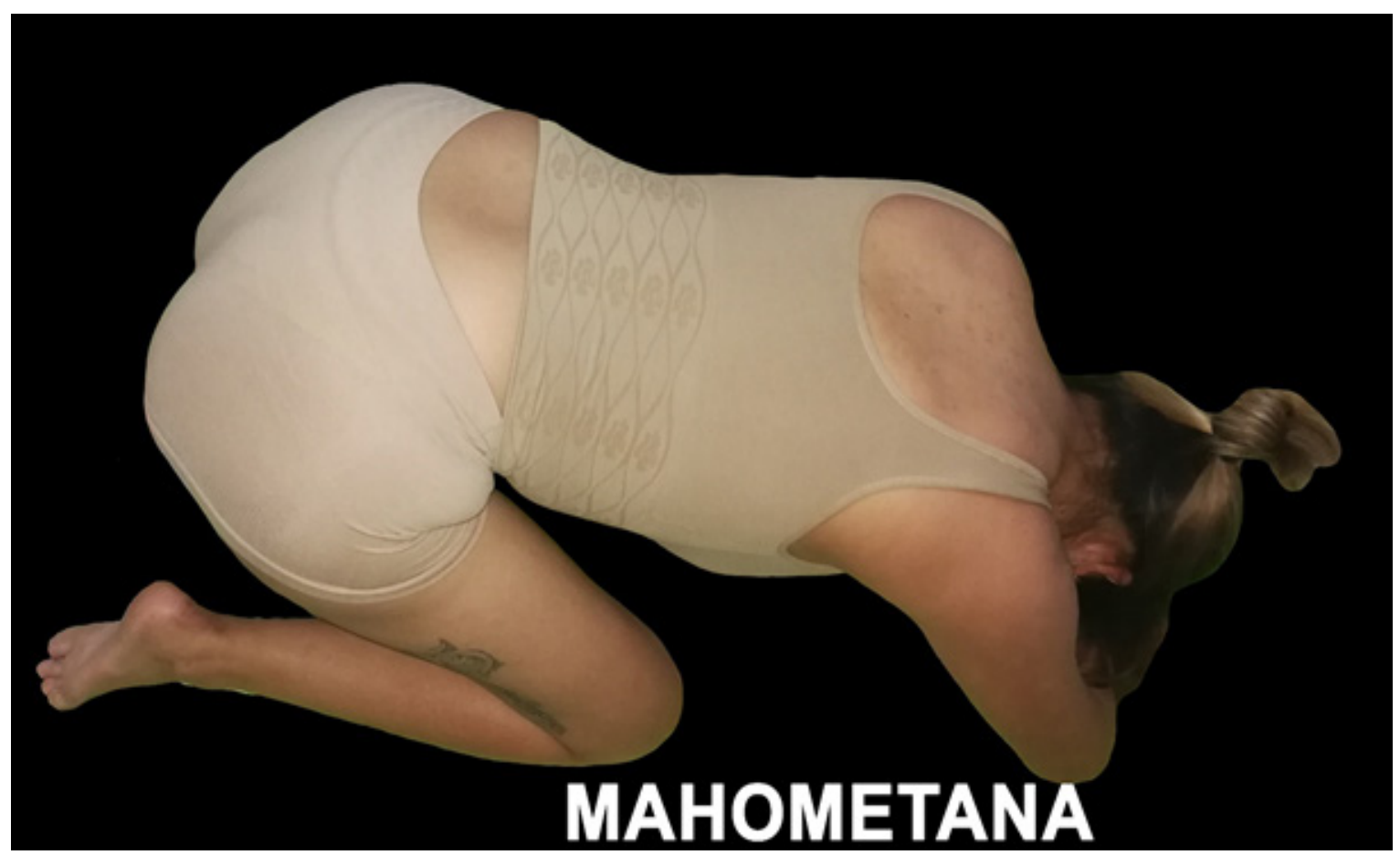

Figura Nro.10

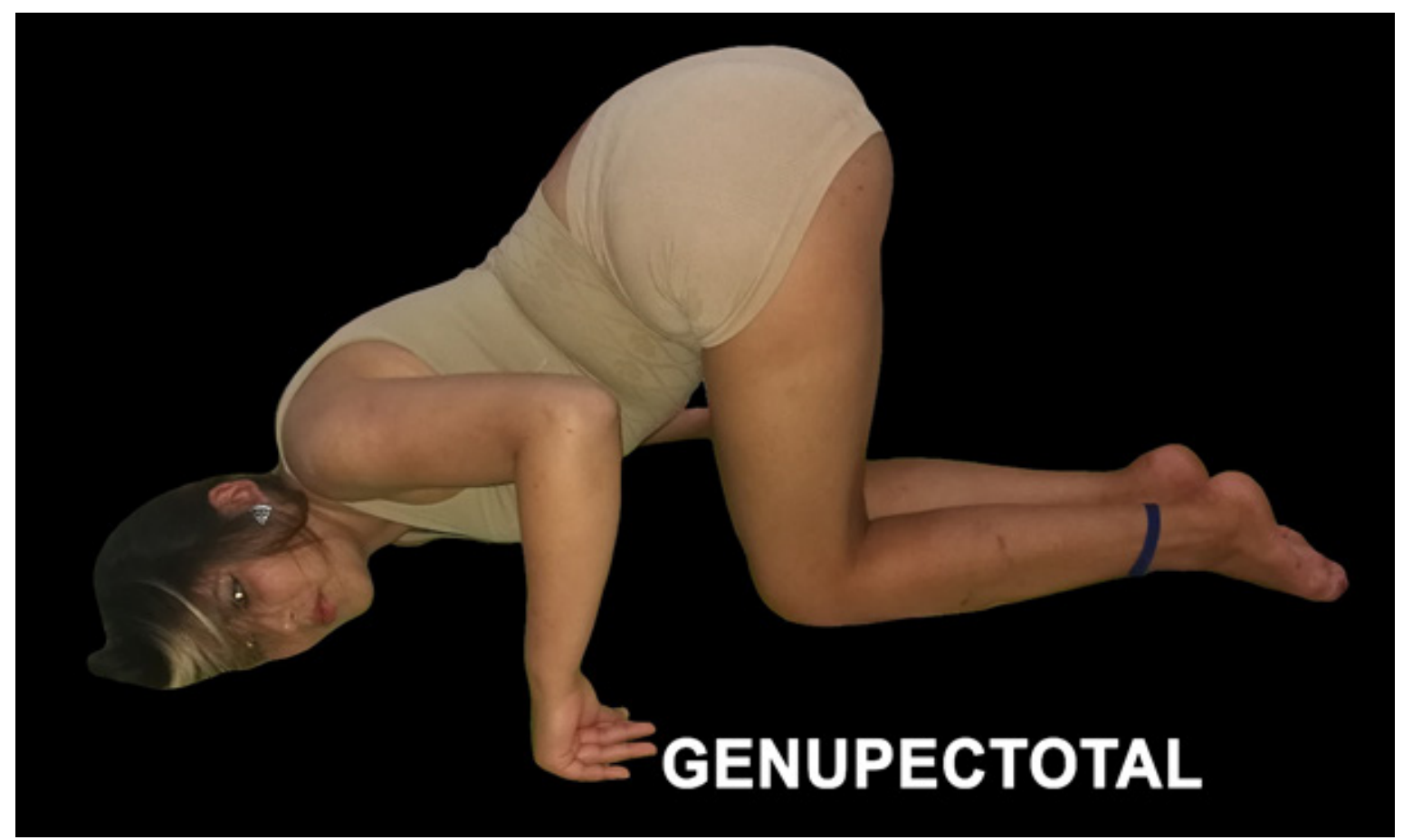

Figura Nro.11 


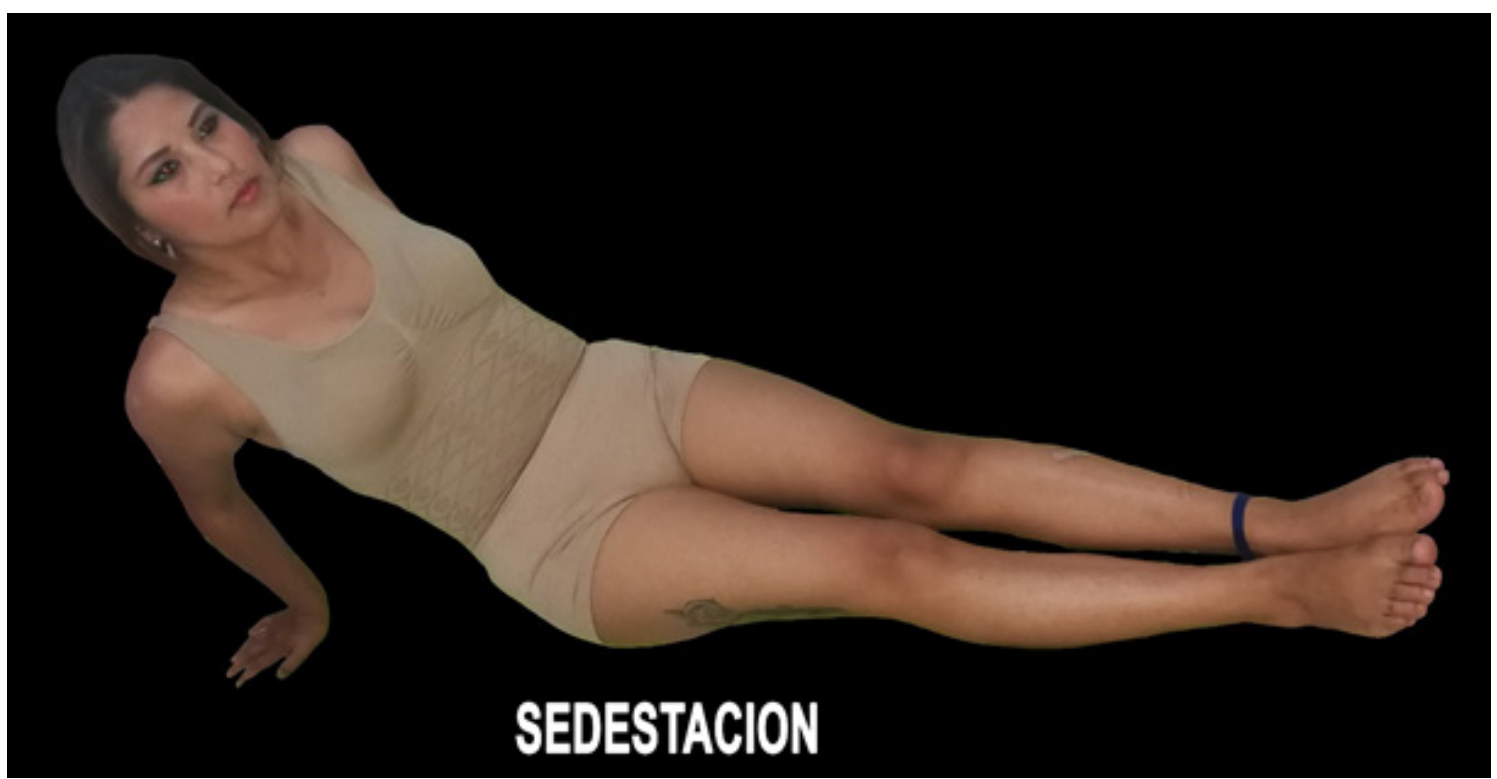

Figura Nro.12

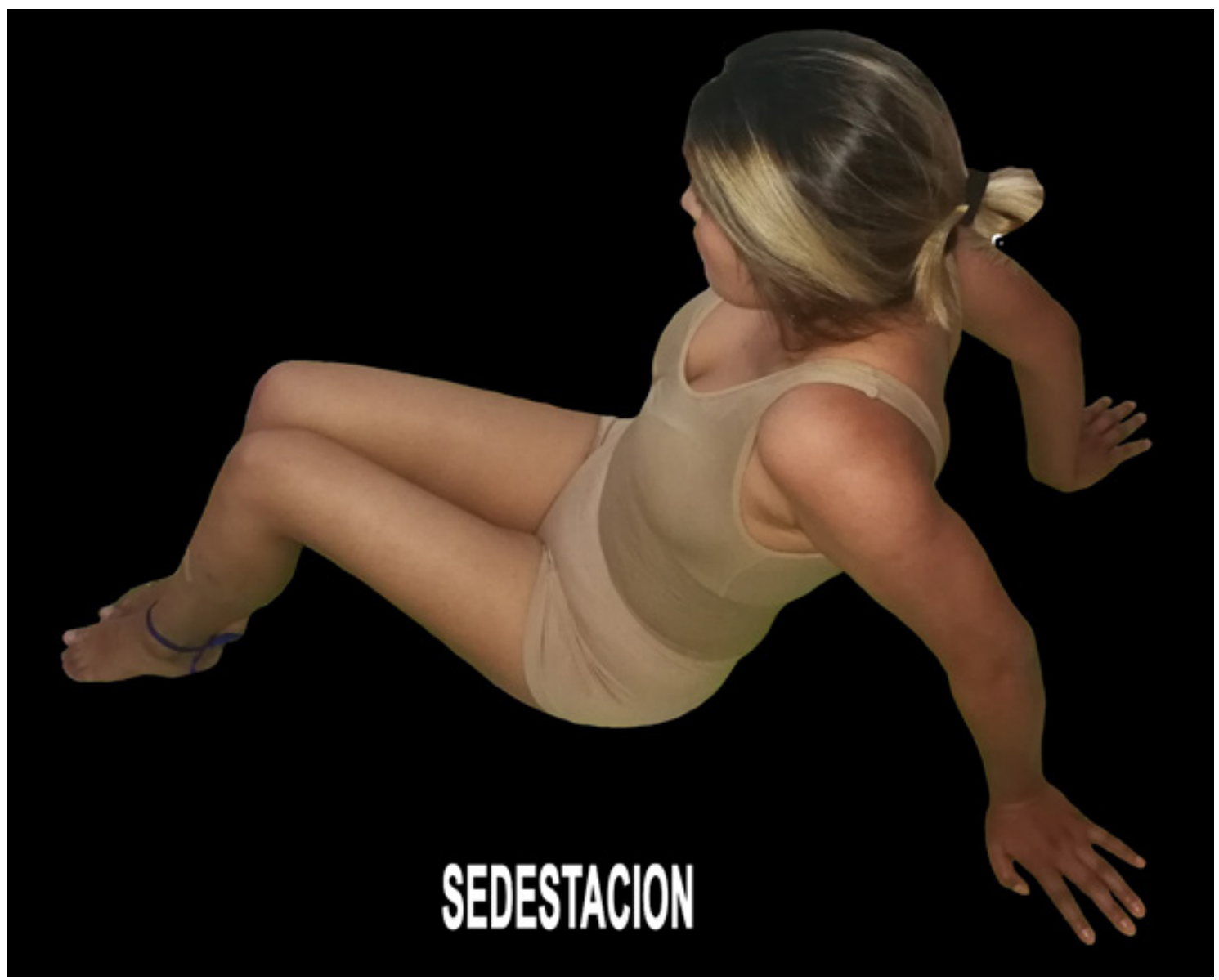

Figura Nro.13 


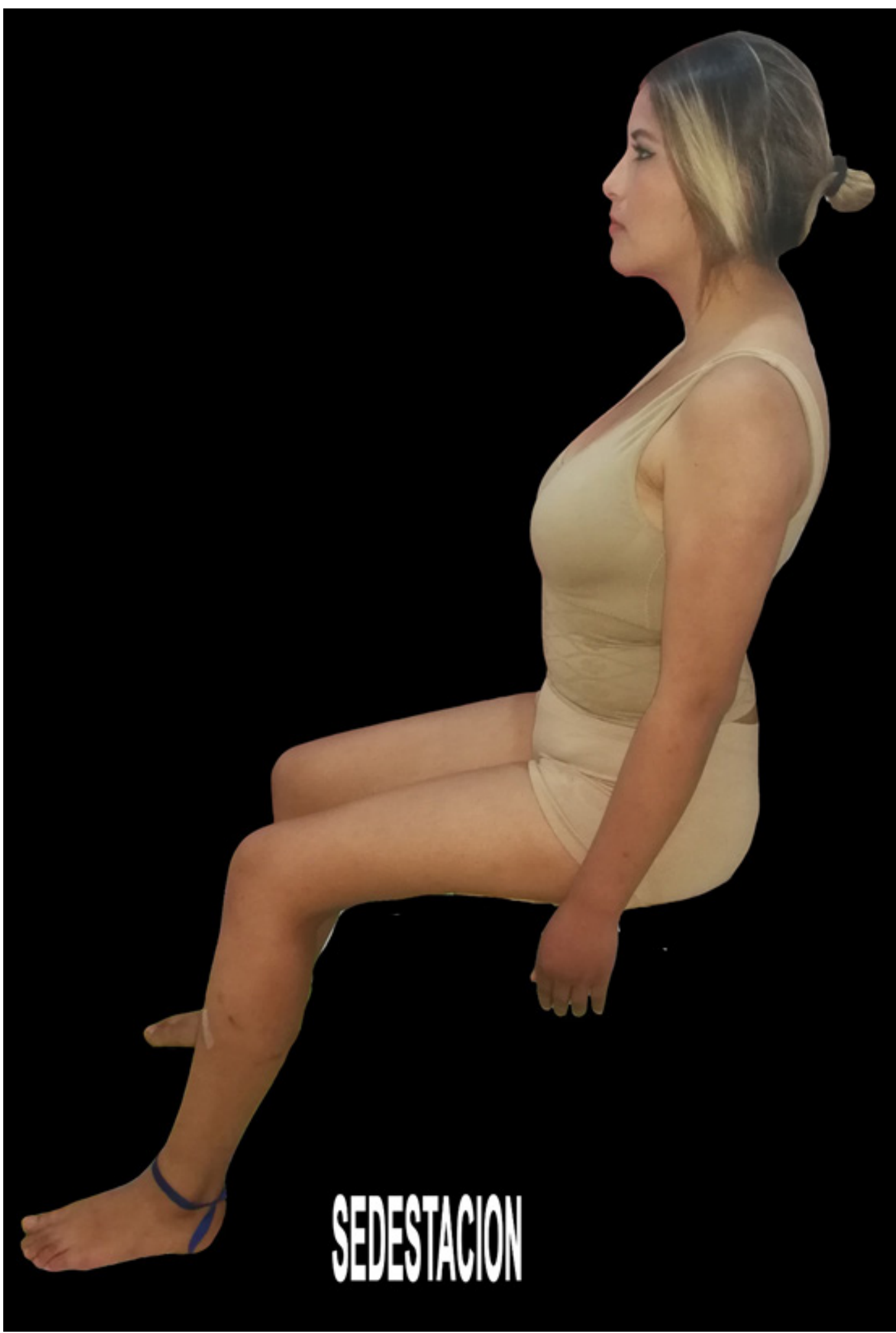

Figura Nro.14

\section{SUSPENSIÓN COMPLETA}

En esta posición encontramos el cadáver suspendido con un agente constrictor alrededor del cuello, el agente constrictor se encuentra fijado o amarrado a un punto fijo. 
Al estar suspendido en forma total no toca el piso con alguna región del cuerpo y los miembros superiores e inferiores cuelgan casi siempre 7.

El agente constrictor puede estar fijado en una regadera, travesaño de madera o metal entre otros ${ }^{14}$. (ver figura Nro.15 y 16).

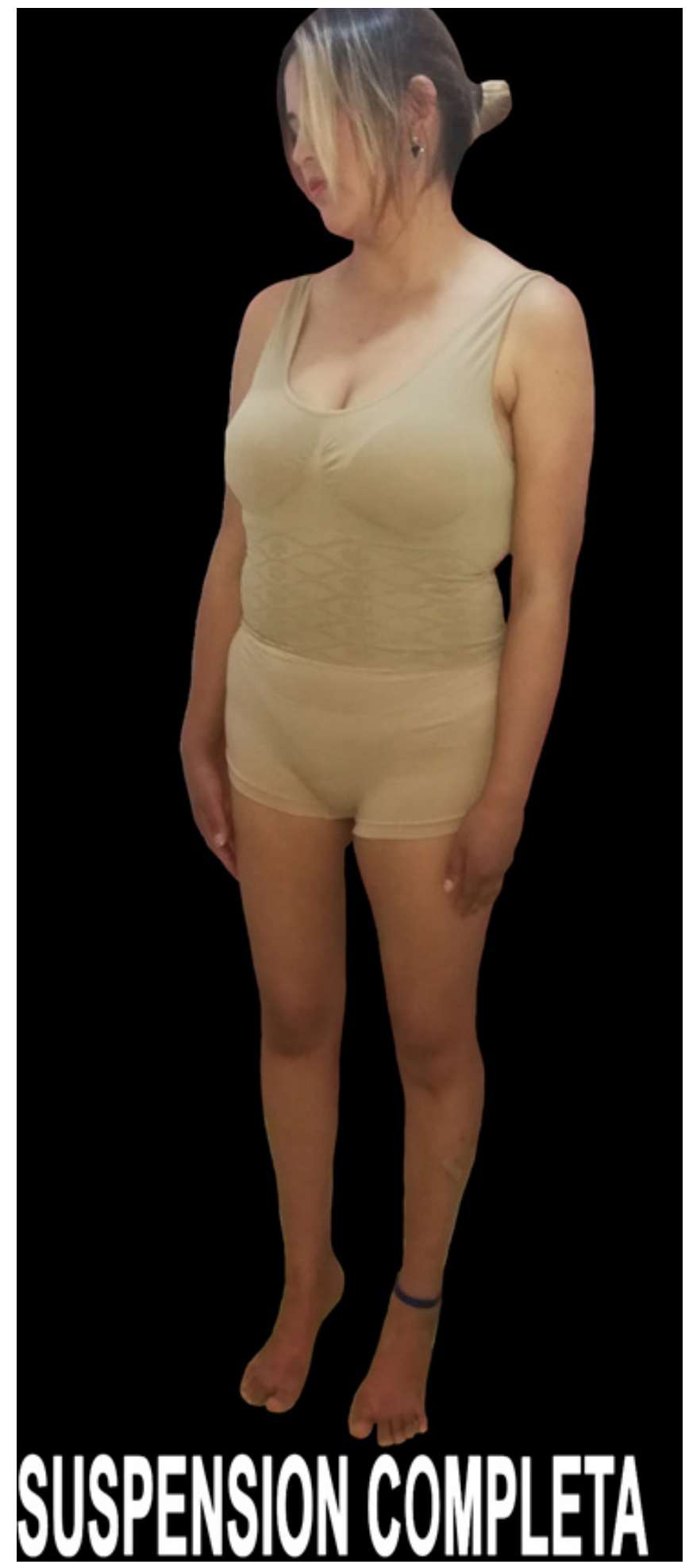

Figura Nro.15 


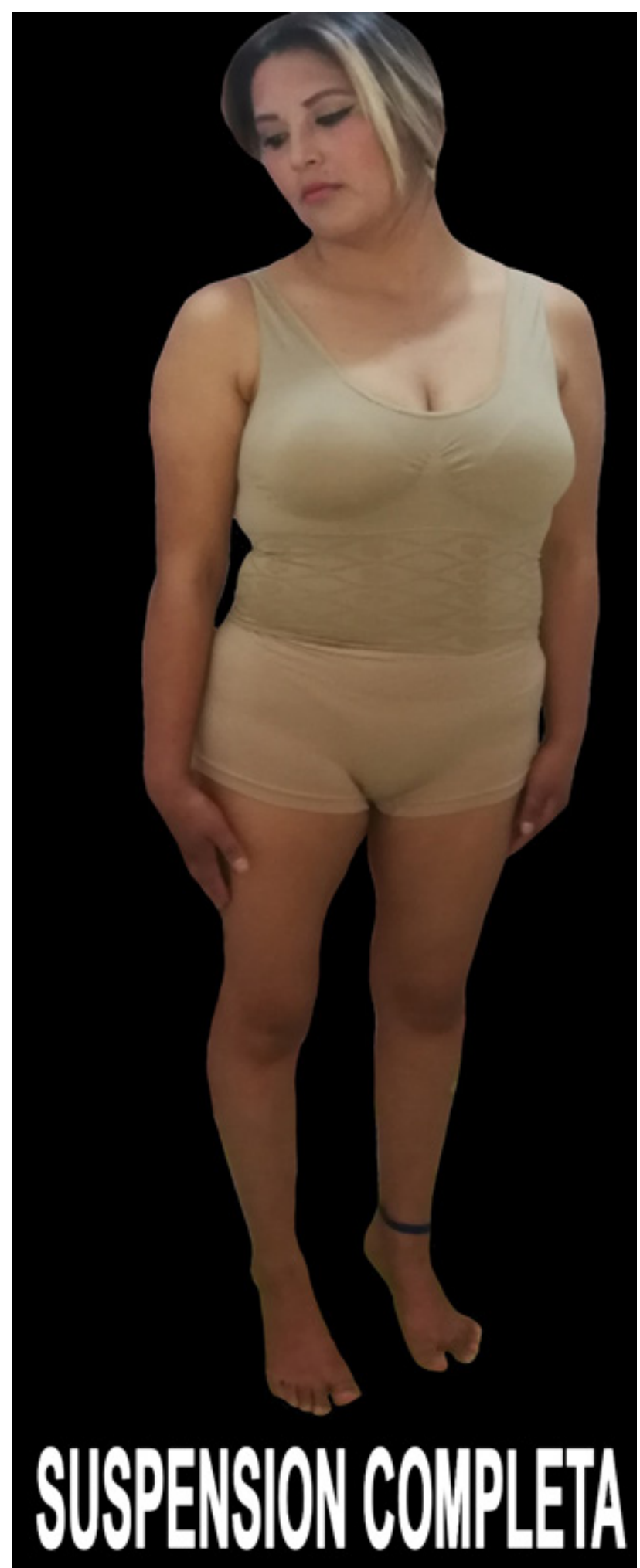

Figura Nro.16

SUSPENSIÓN COMPLETA INVERTIDA

Es una posición en la que el cadáver está suspendido cabeza abajo atado por las piernas con el agente constrictor y sin que el cuerpo toque el suelo. (ver figura Nro.17 
y 18).

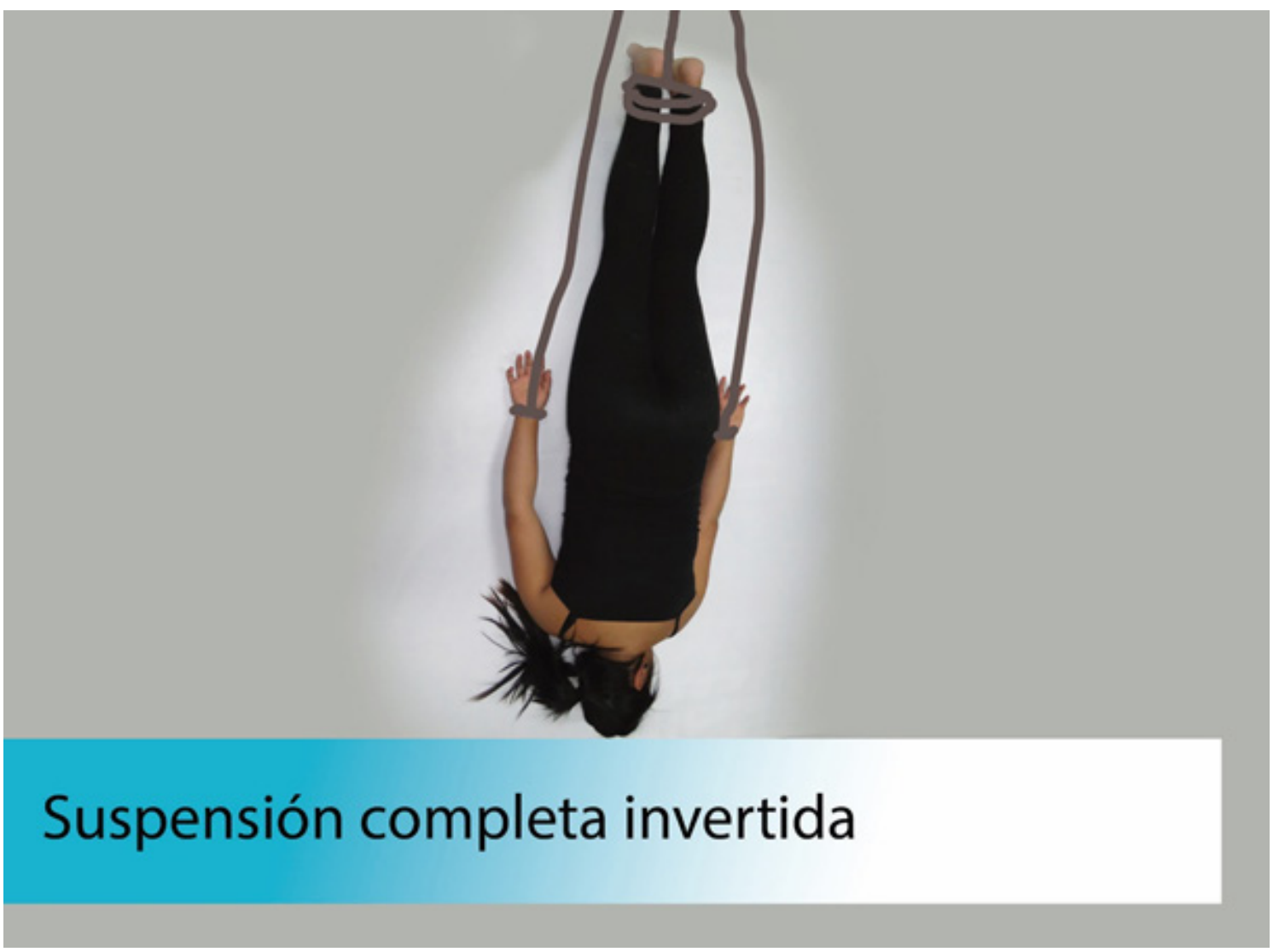

Figura Nro.17

\section{SUSPENSIÓN INCOMPLETA}

En esta posición encontramos el cadáver suspendido con un agente constrictor alrededor del cuello, el agente constrictor se encuentra fijado o amarrado a un punto fijo. El cadáver se encuentra con una parte del cuerpo tocando el piso, generalmente pies o rodillas. Casi siempre los miembros superiores cuelgan hacia abajo, pero los inferiores se flexionan por el contacto que en general tienen con el piso o con otro soporte $o$ mueble $^{7}$. (ver figuras Nro. 19 al 25).

\section{SUMERSIÓN COMPLETA}

En esta posición el cuerpo se encuentra sumergido dentro de líquido, como piscinas, ríos, pozos, etc. El cuerpo puede encontrarse boca abajo o boca arriba ${ }^{8}$.

El cuerpo de las personas que pierde la vida por asfixia por sumersión, adquiere la forma o figura conocida como posición de luchador, y se puede observar cuando todavía hay rigidez cadavérica dentro de los grandes recipientes se aprecien boca abajo debido a la ubicación de los pulmones que, no obstante, conservan algo de aire en sus alveolos y tienden a flotar (ver figuras Nro. 26 y 27).

\section{SUMERSIÓN INCOMPLETA}

Es la posición final del cuerpo de personas que pierden la vida por asfixia por sumersión incompleta, consistente en la sumersión de las regiones superiores corporales, sobre todo la cabeza, en la que se ubican los orificios de aireación, dentro de recipien- 
tes medianos con líquidos, por lo general agua, como tinas de baño, tinas de ropa, tinacos, pilas, cubetas, etcétera. Las partes inferiores del cuerpo quedan hacia fuera del recipiente ${ }^{8 .}$ (ver figuras Nro. 28 y 29 ).

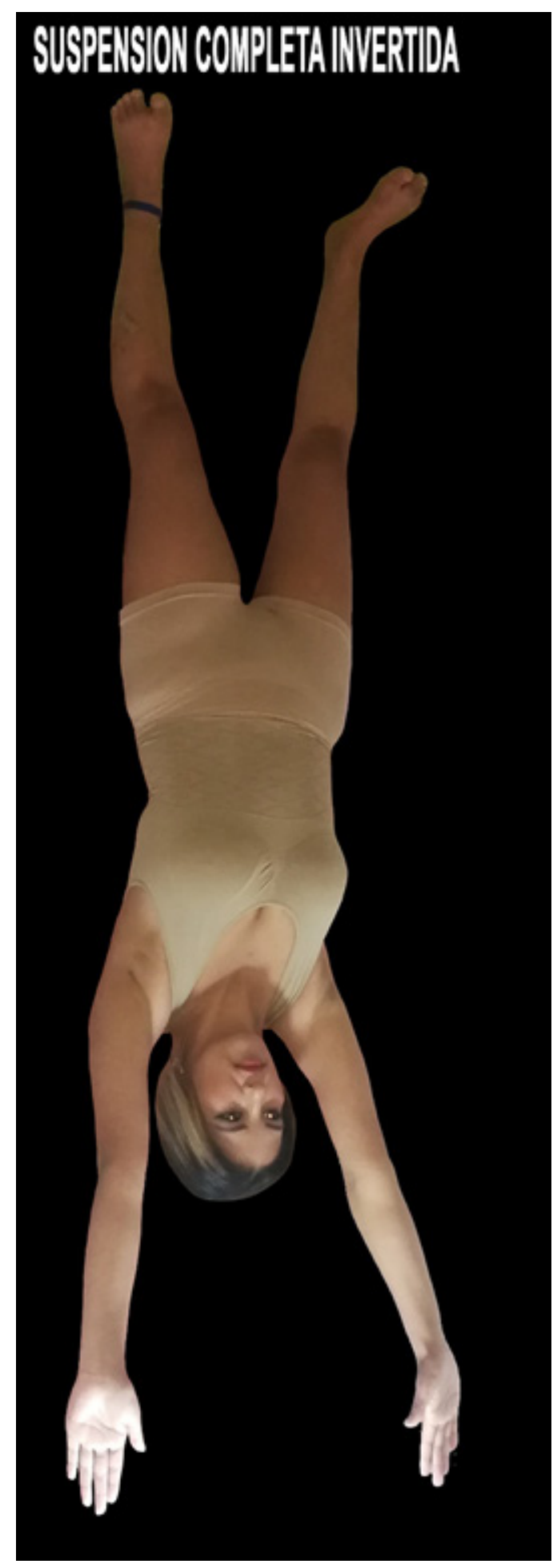

Figura Nro.18 


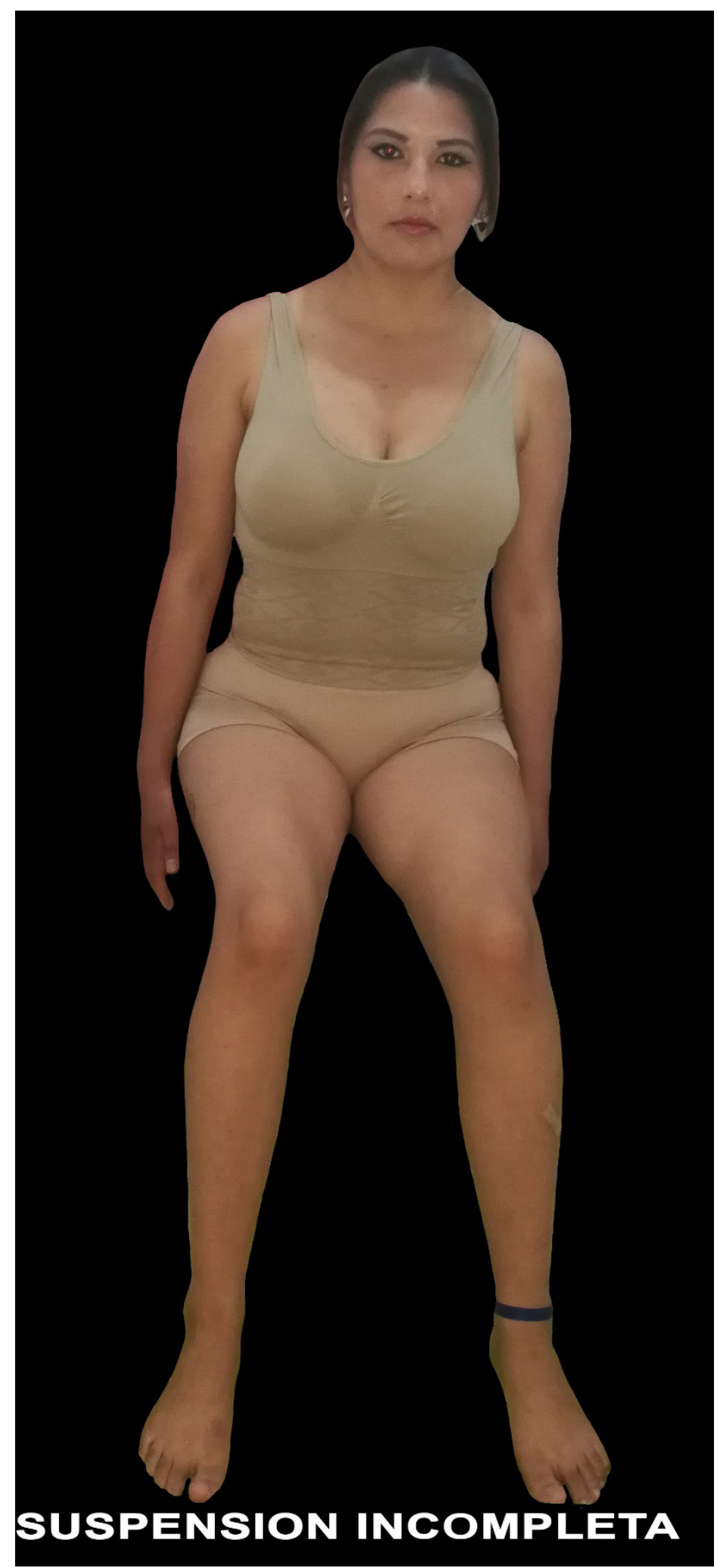

Figura Nro.19 


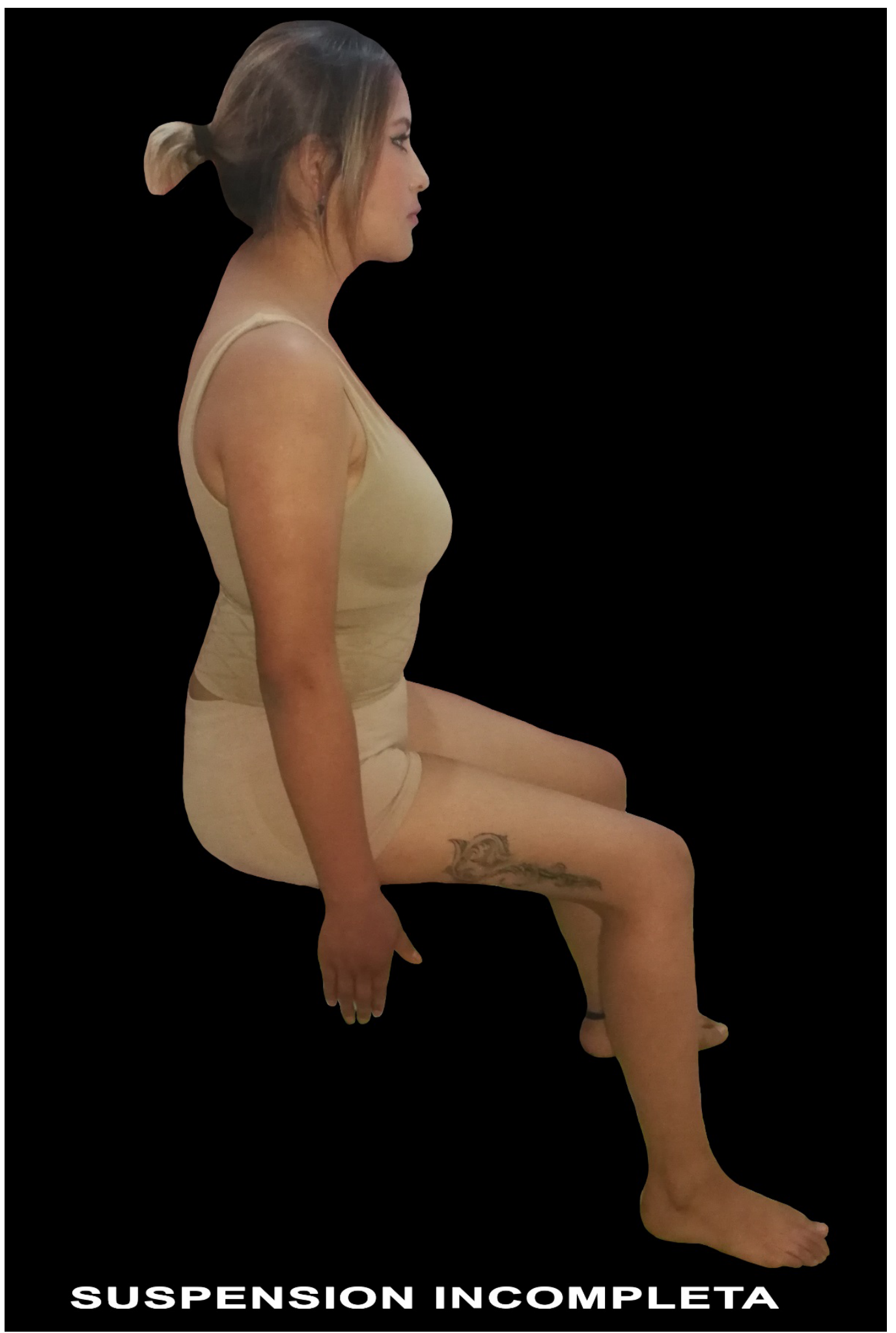

Figura Nro. 20 


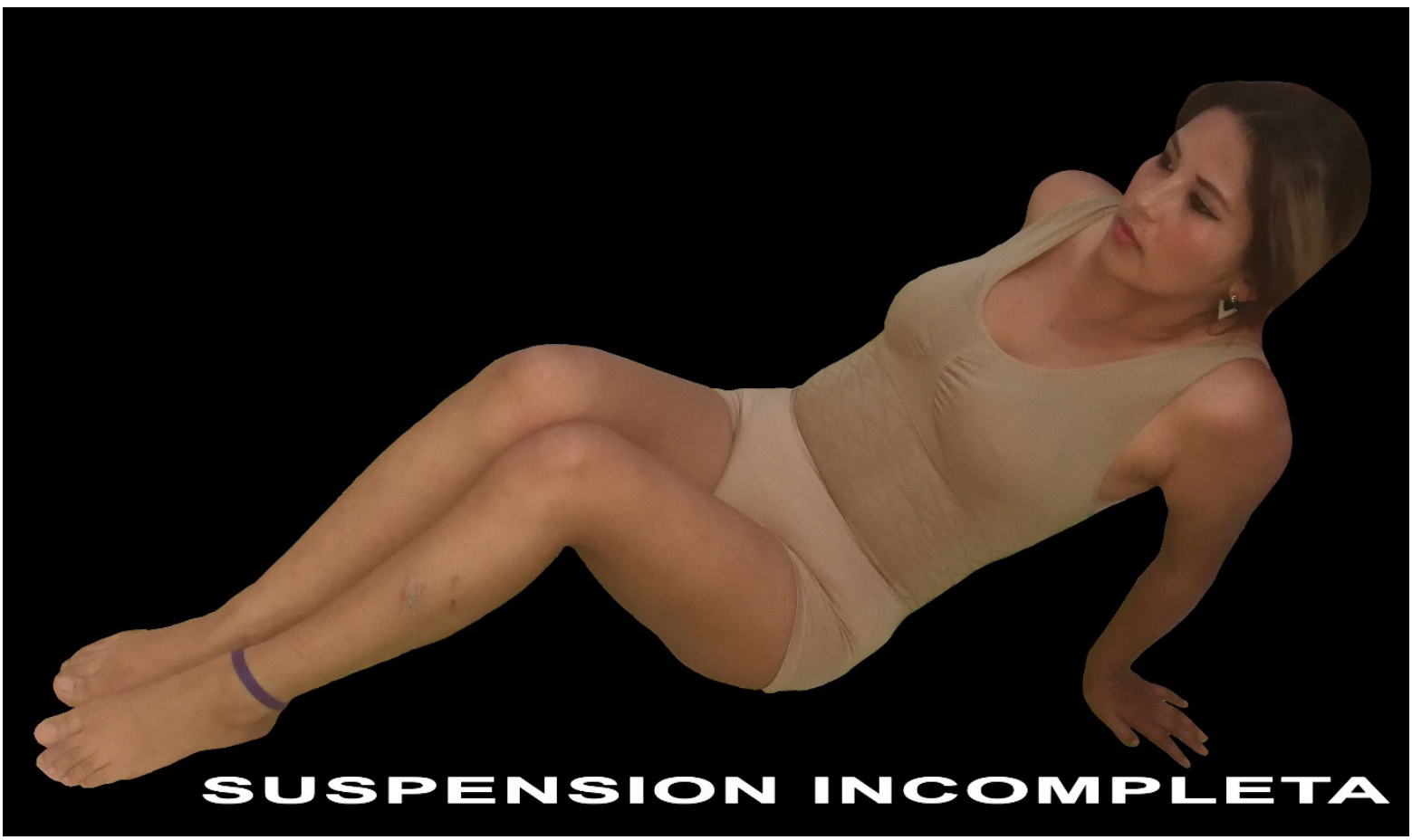

Figura Nro. 22 


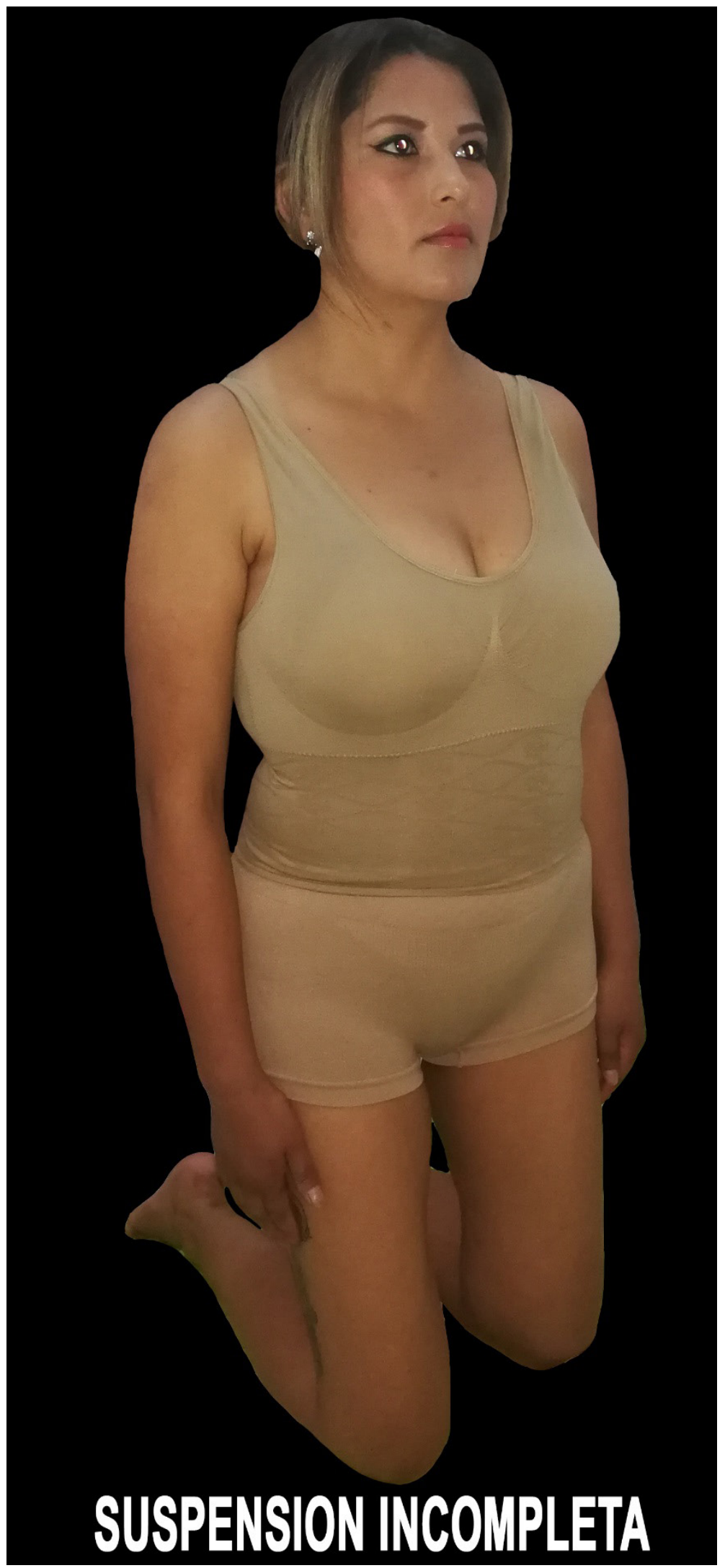

Figura Nro. 23 


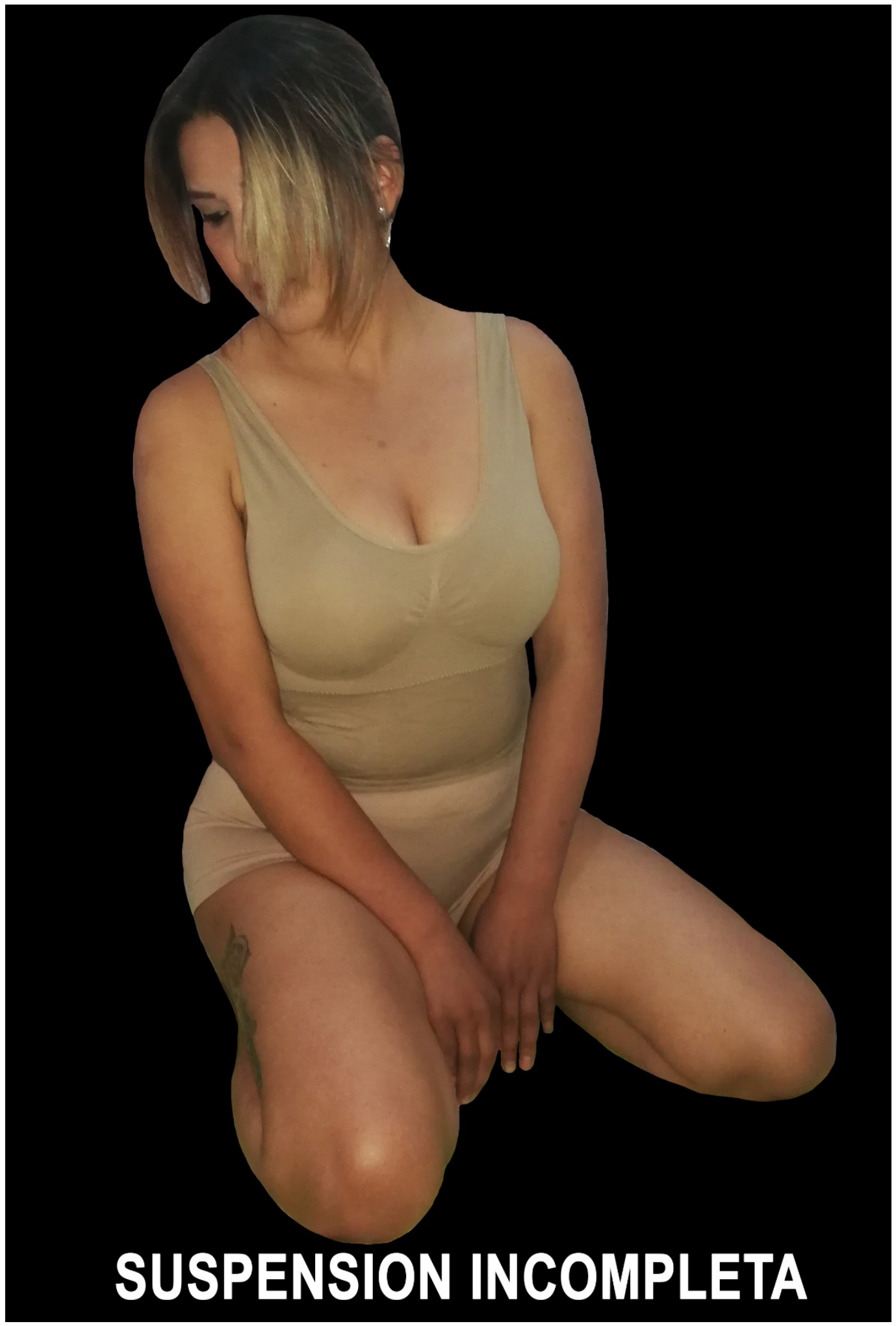

Figura Nro. 24 
Revista Científica de Salud UNITEPC

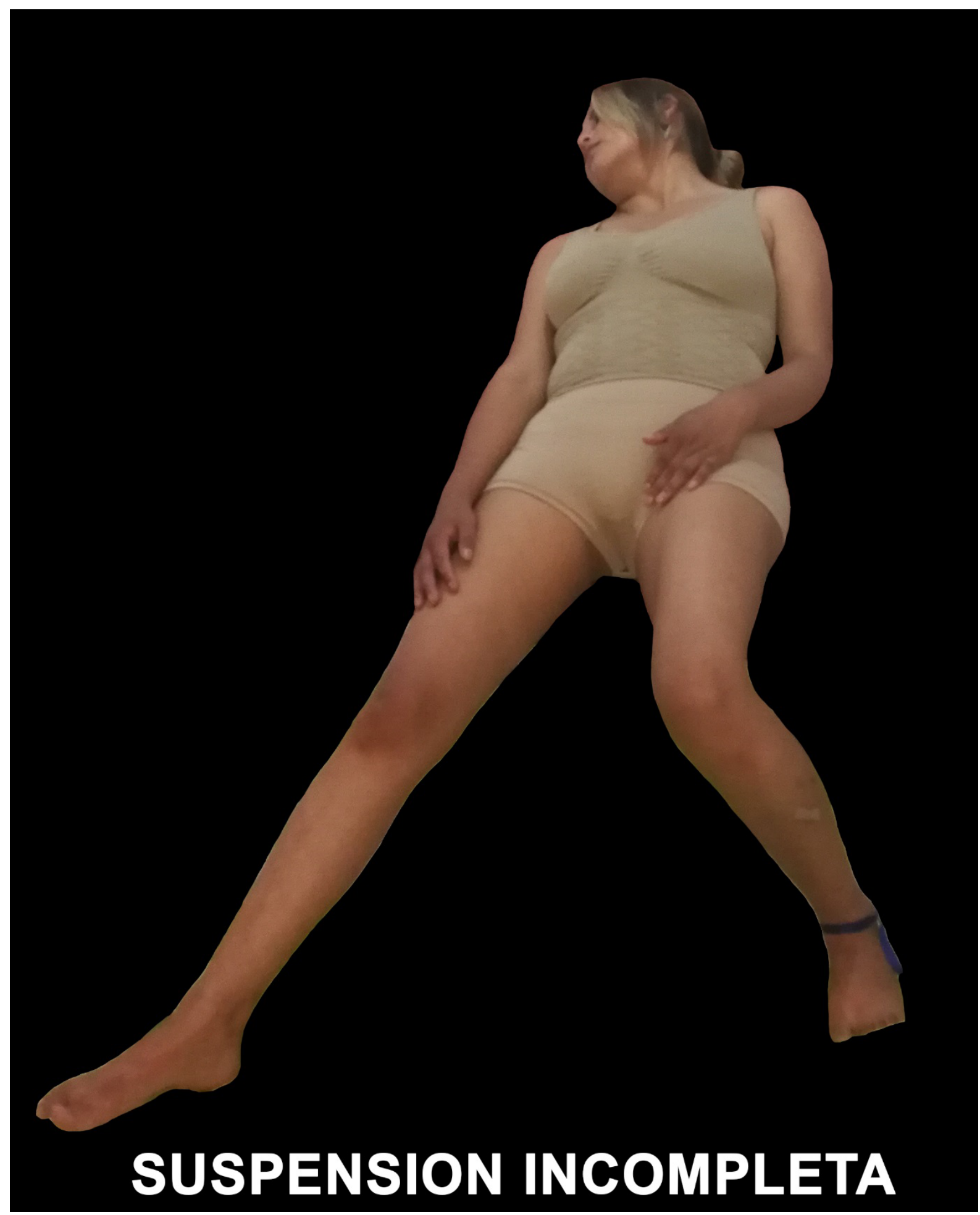

Figura Nro. 25 
Figura Nro. 26 
Revista Científica de Salud UNITEPC

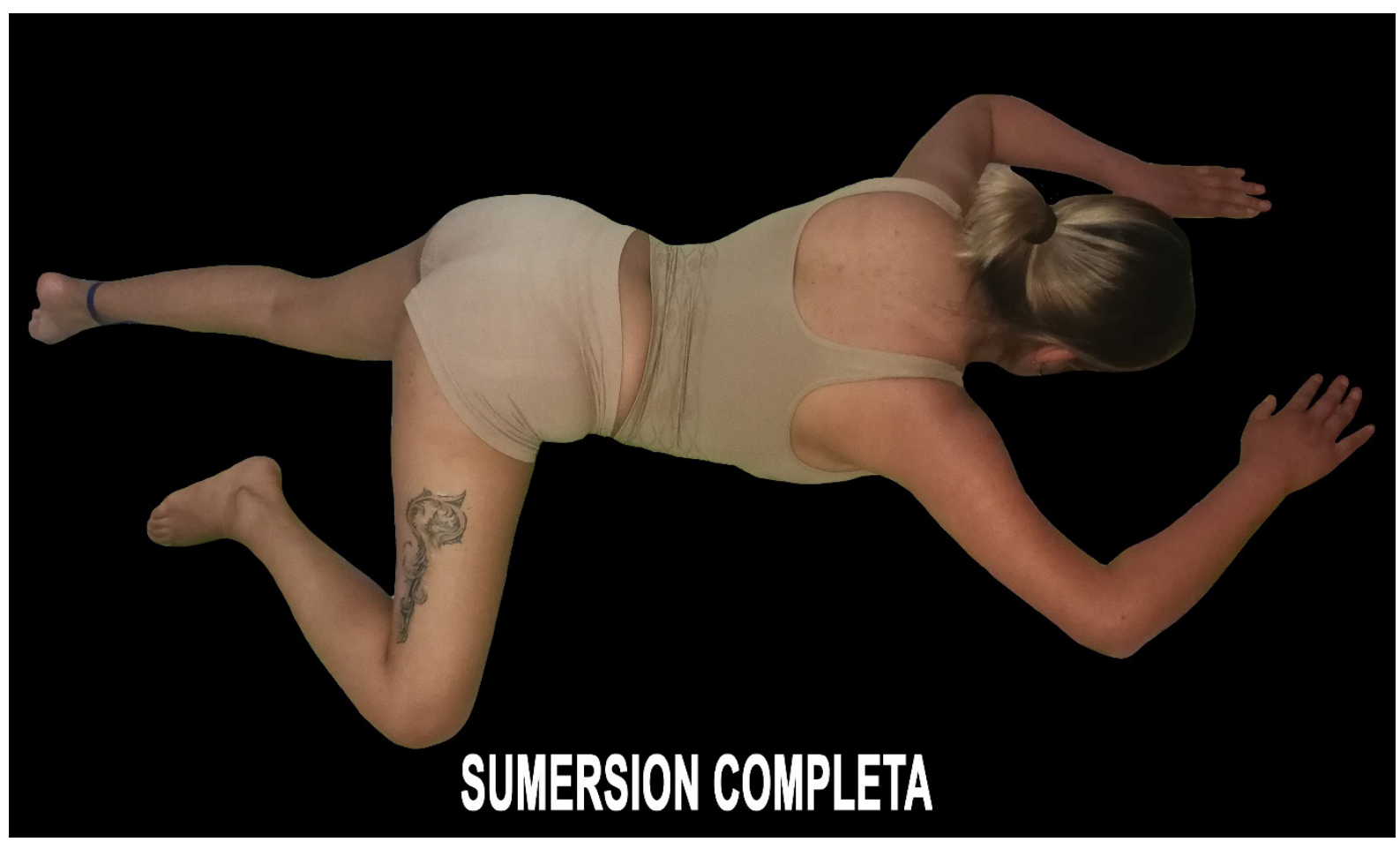

Figura Nro. 27

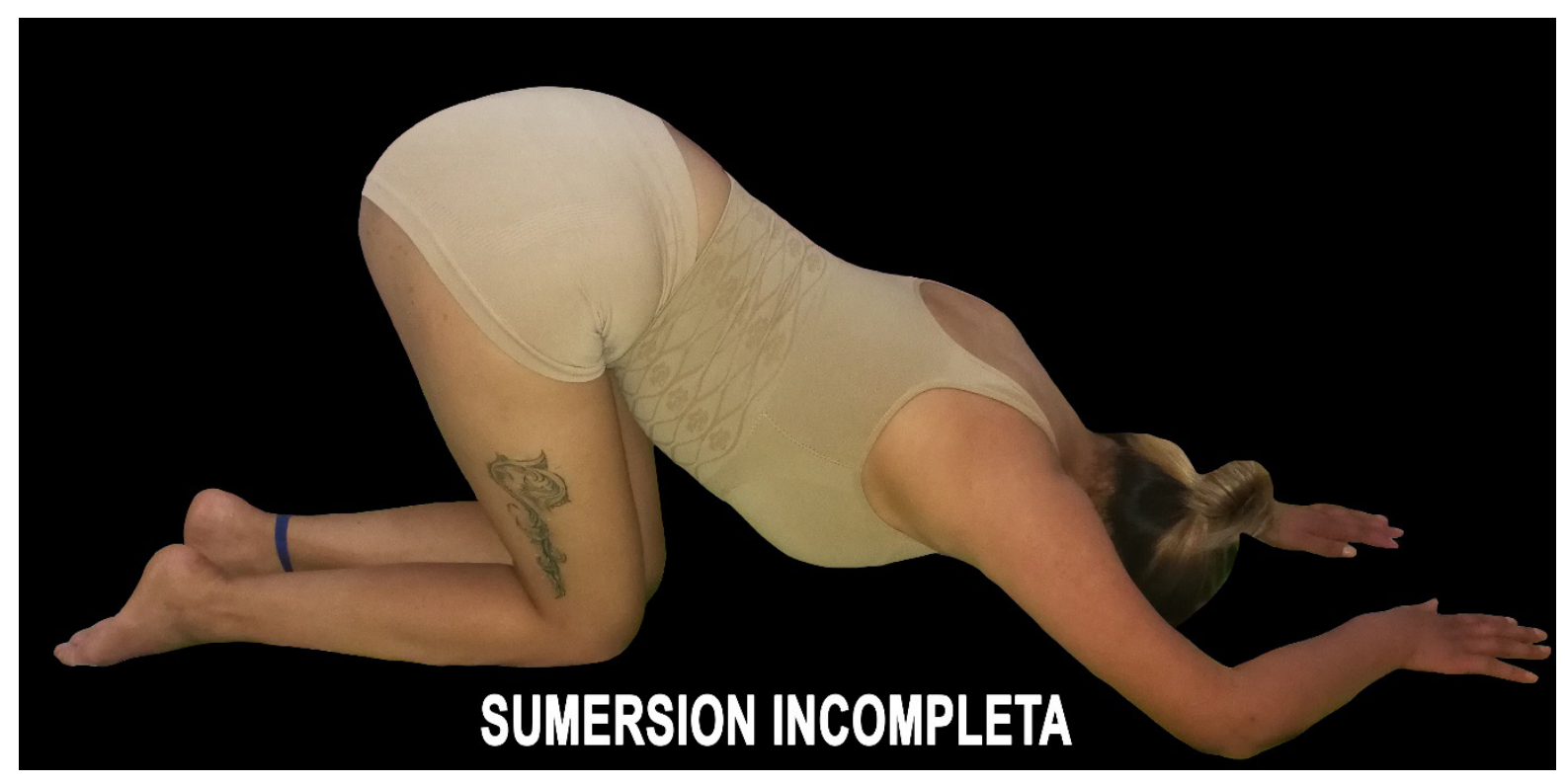

Figura Nro. 28 


\section{Revista Científica de Salud UNITEPC}

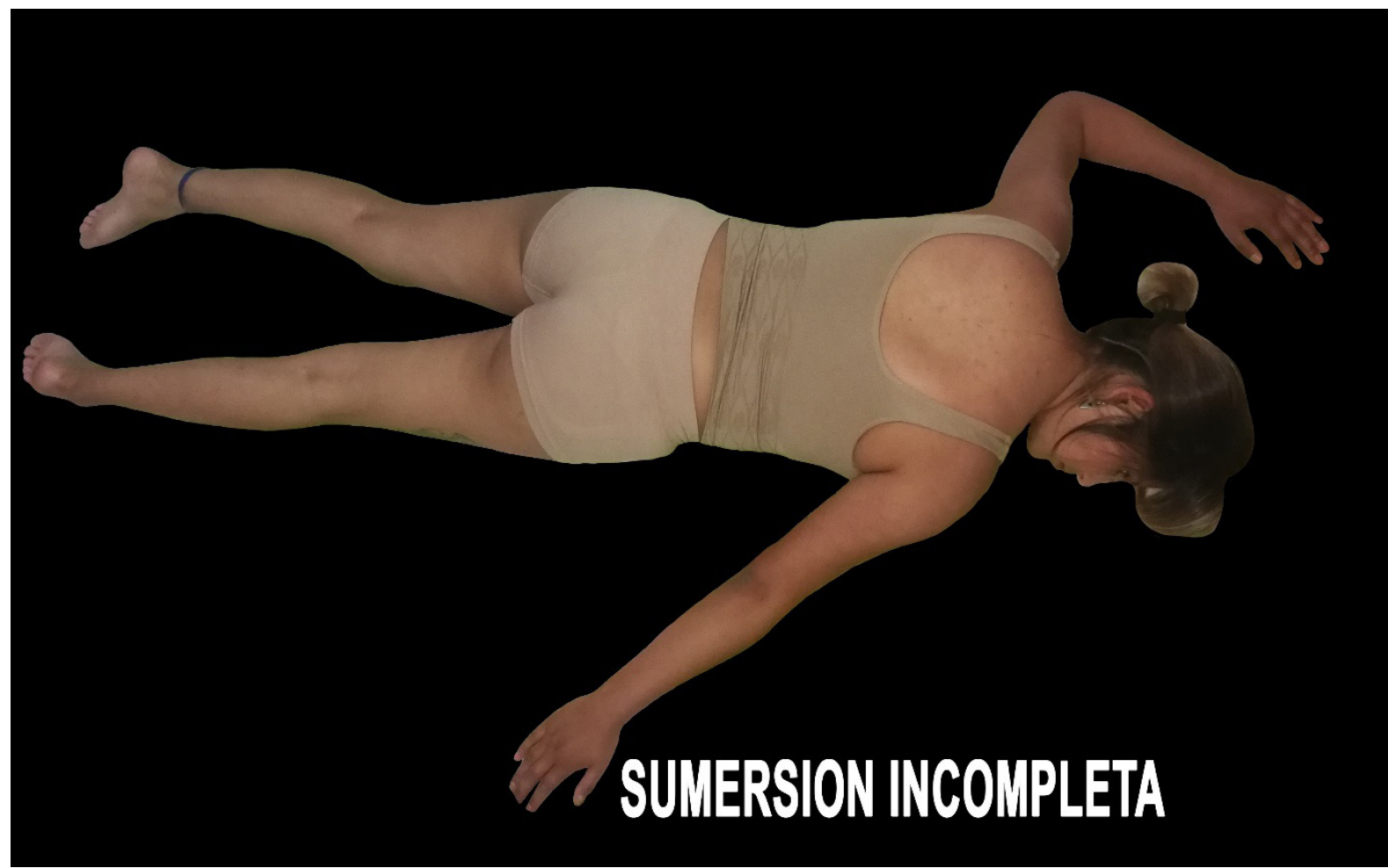

Figura Nro. 29

POSICIÓN DE ROSER O PROETZ

Posición cadavérica donde la cabeza queda en un plano inferior al cuerpo ${ }^{8}$ (ver figuras Nro. 30 y 31).

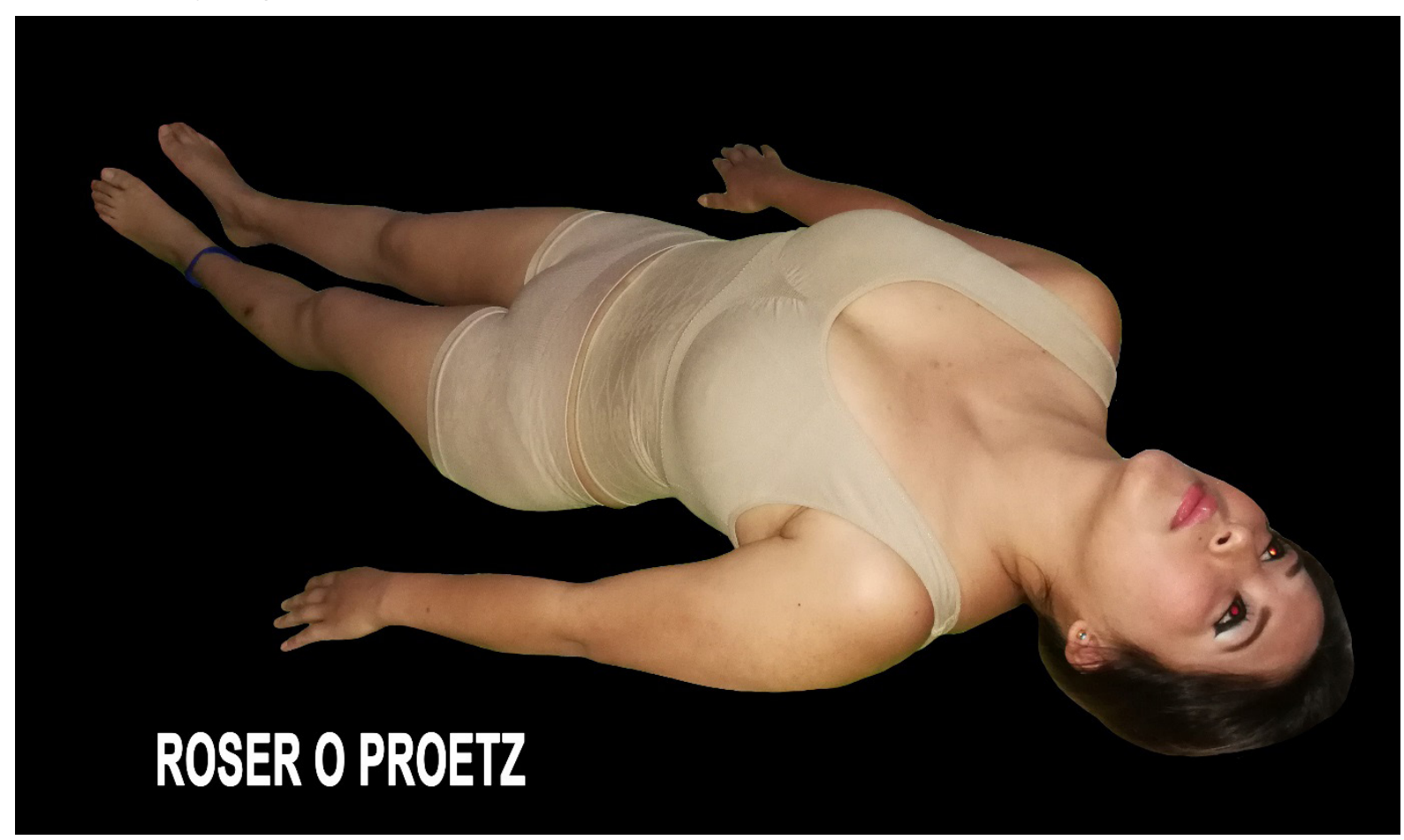

Figura Nro. 30 


\section{Revista Científica de Salud UNITEPC}

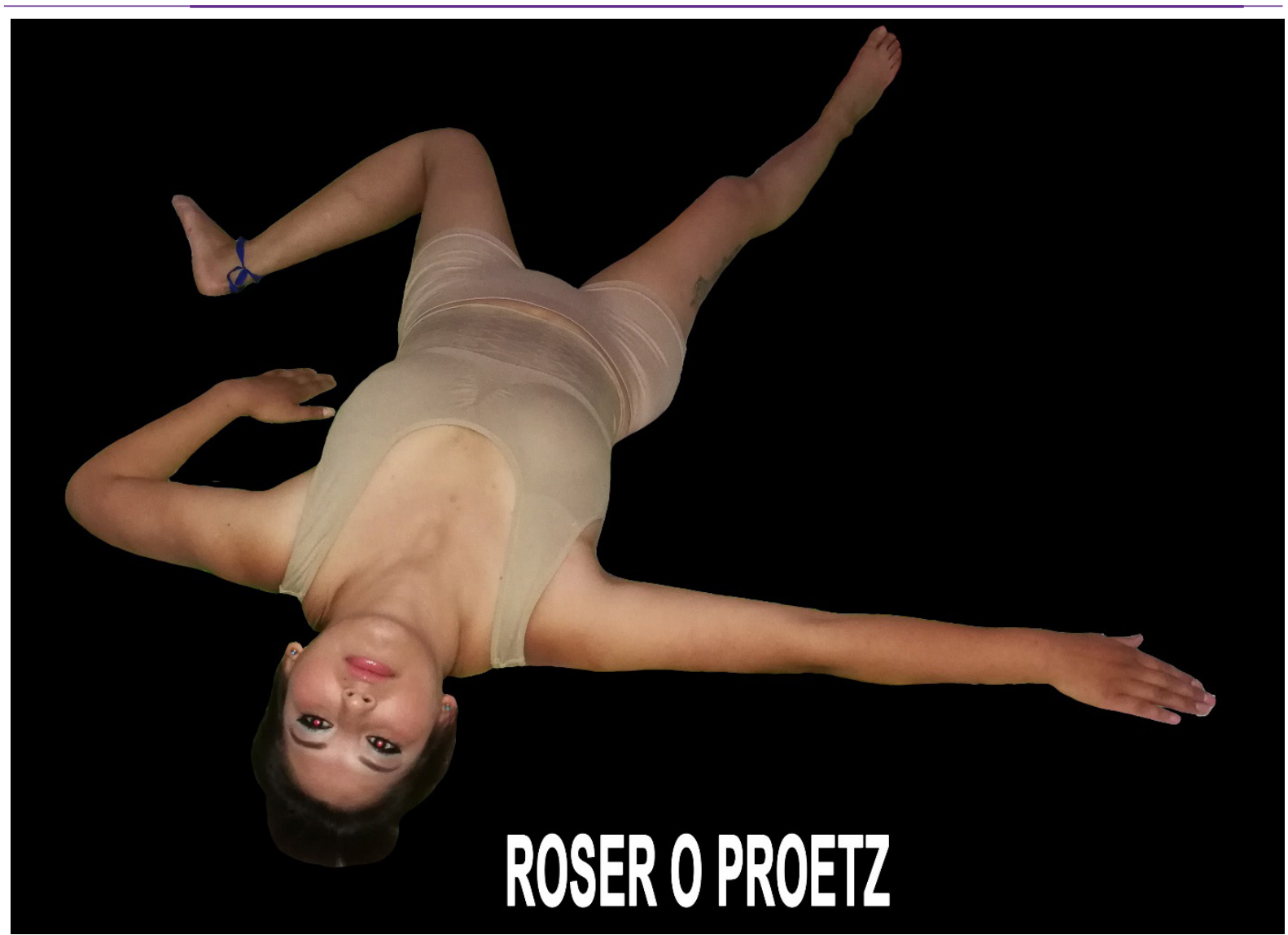

Figura Nro. 31

\section{POSICIÓN DE BOXEADOR}

Esta posición es característica de los cadáveres calcinados, esto se debe a la deshidratación y contracción de los músculos que se origina por el calor o fuego directo que reciben con gran intensidad. Se asemeja a un boxeador en posición de defensa ${ }^{9}$. (ver figura Nro. 34).

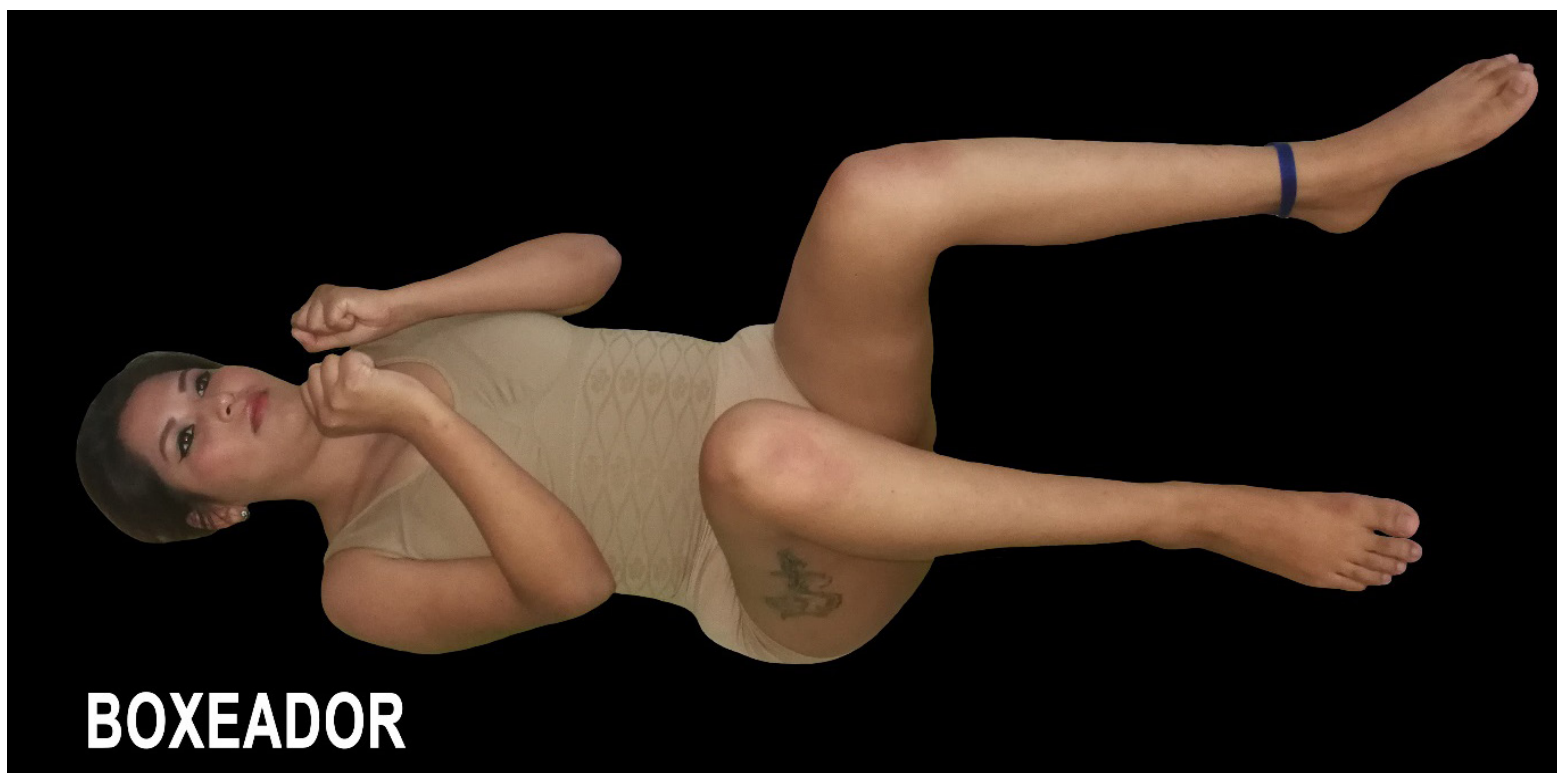

Figura Nro. 32 


\section{TÓNICO-CERVICAL ASIMÉTRICO (ESGRIMISTA)}

Esta posición cadavérica también se encuentra en cuerpos carbonizados, donde se encuentra el cuerpo en decúbito dorsal con un miembro superior extendido y el otro flexionado y con los miembros inferiores en abducción en sentido contrario a los miembros superiores $^{9 .}$ (ver figura Nro. 33).

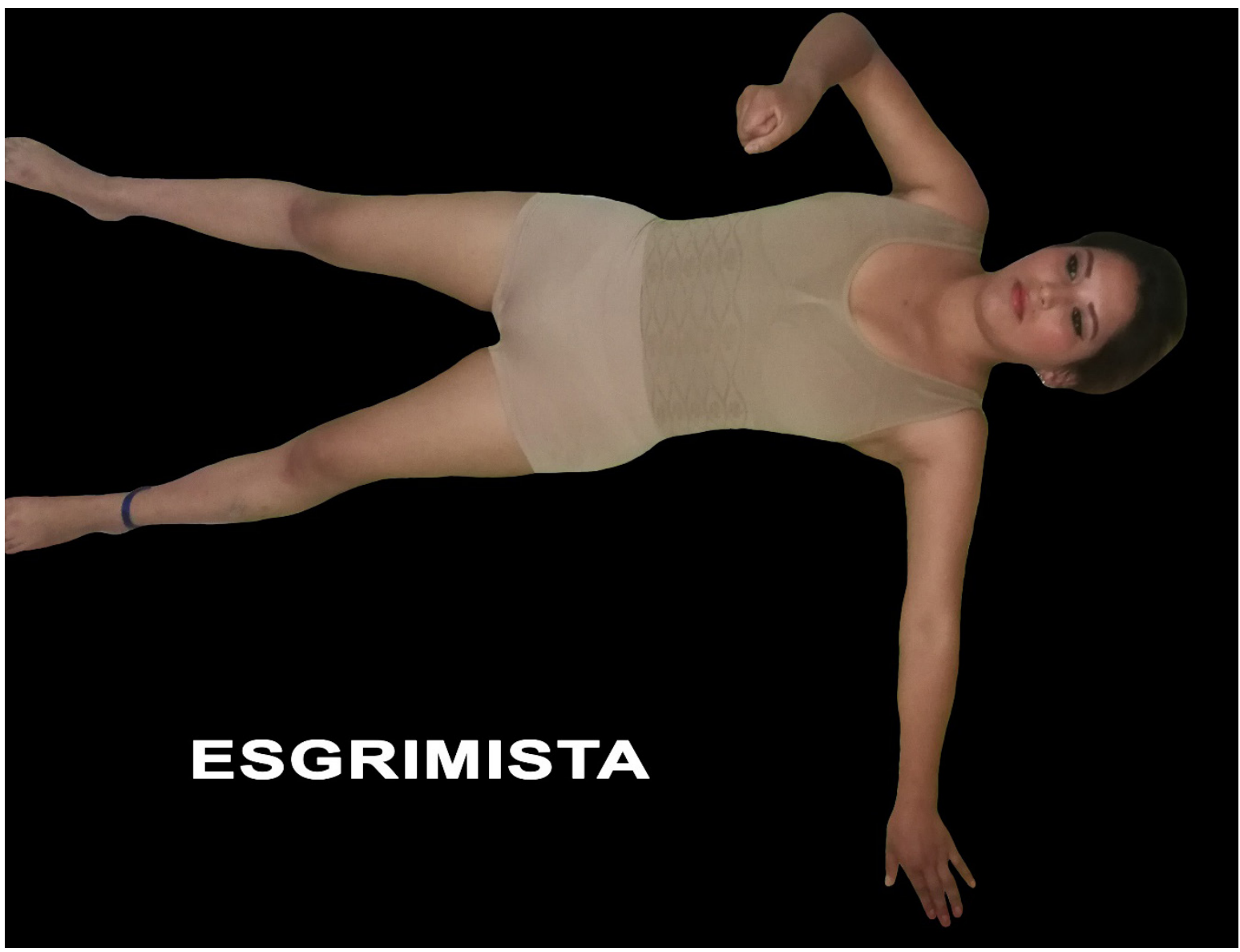

Figura Nro. 33

\section{POSICIÓN FETAL}

Es la posición final que adquieren algunos cuerpos humanos que son metidos completos dentro de contenedores o muebles grandes, tales como baúles, cajas, refrigeradores, closets pequeños, tinacos, tinas, etcétera. Las figuras se asemejan a productos en el seno materno, en posición de encogida por completo, las extremidades inferiores flexionadas hacia arriba en dirección al abdomen y las superiores flexionadas hacia adentro en abducción al tórax ${ }^{9 .}$ (ver figura Nro. 34 al 36). 


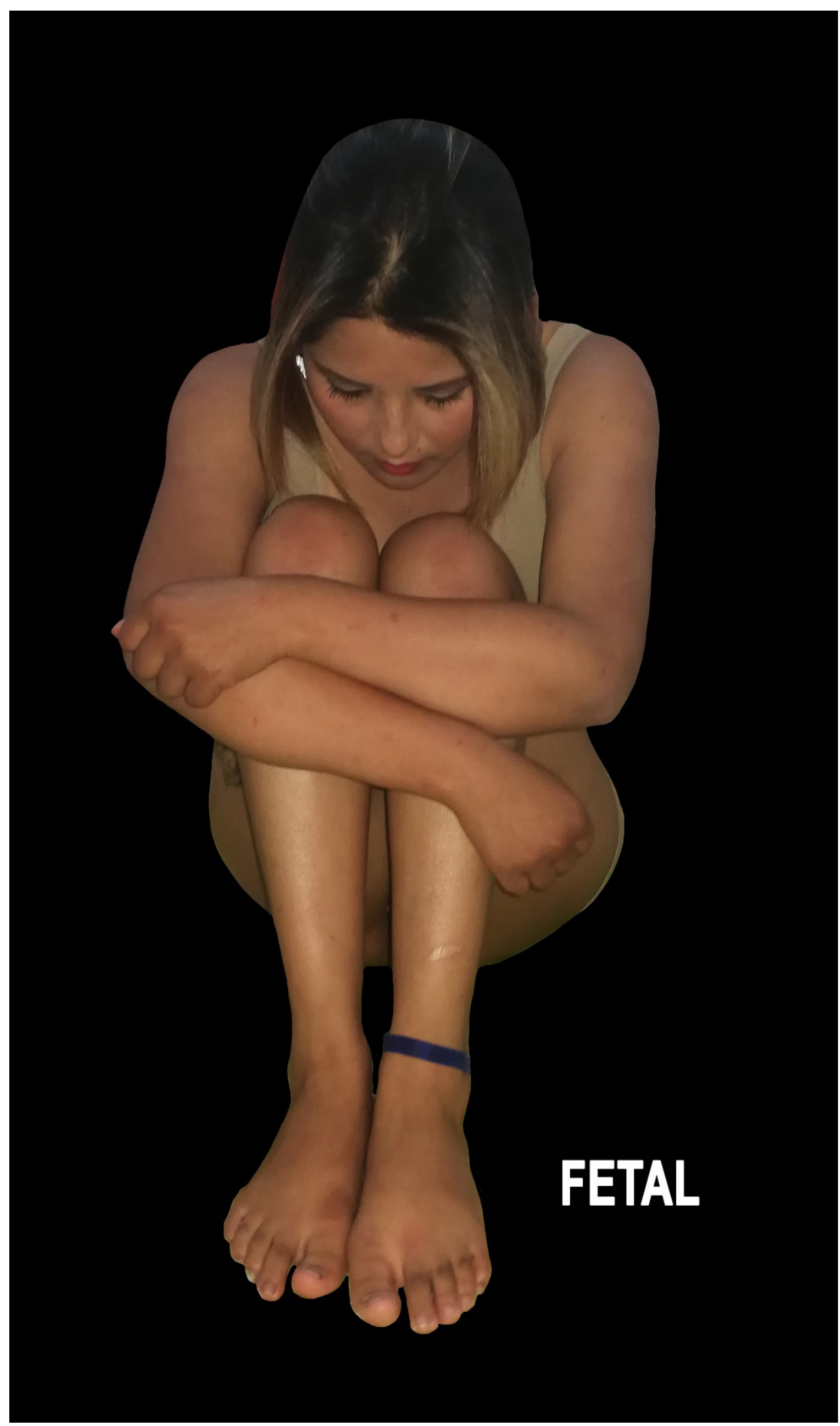

Figura Nro. 34 


\section{FETAL}

Figura Nro. 35 


\section{Revista Científica de Salud UNITEPC}

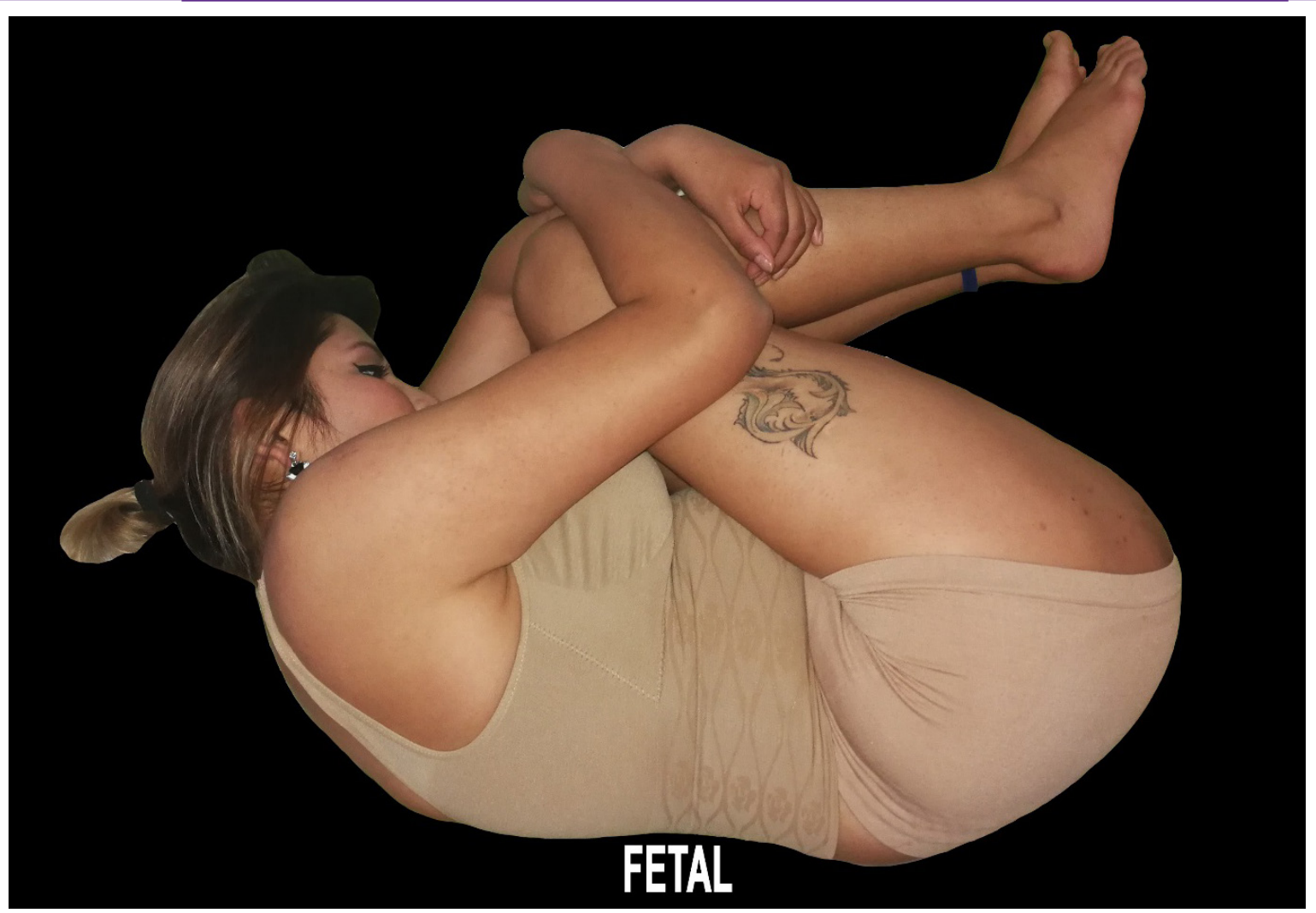

Figura Nro. 36

\section{POSICION DE DEPAGE O KRASKE}

Es la posición prona en $\mathrm{V}$ invertida, cuyo vértice es la pelvis y las ramas del tronco las extremidades inferiores ${ }^{14}$. (ver figura Nro. 37).

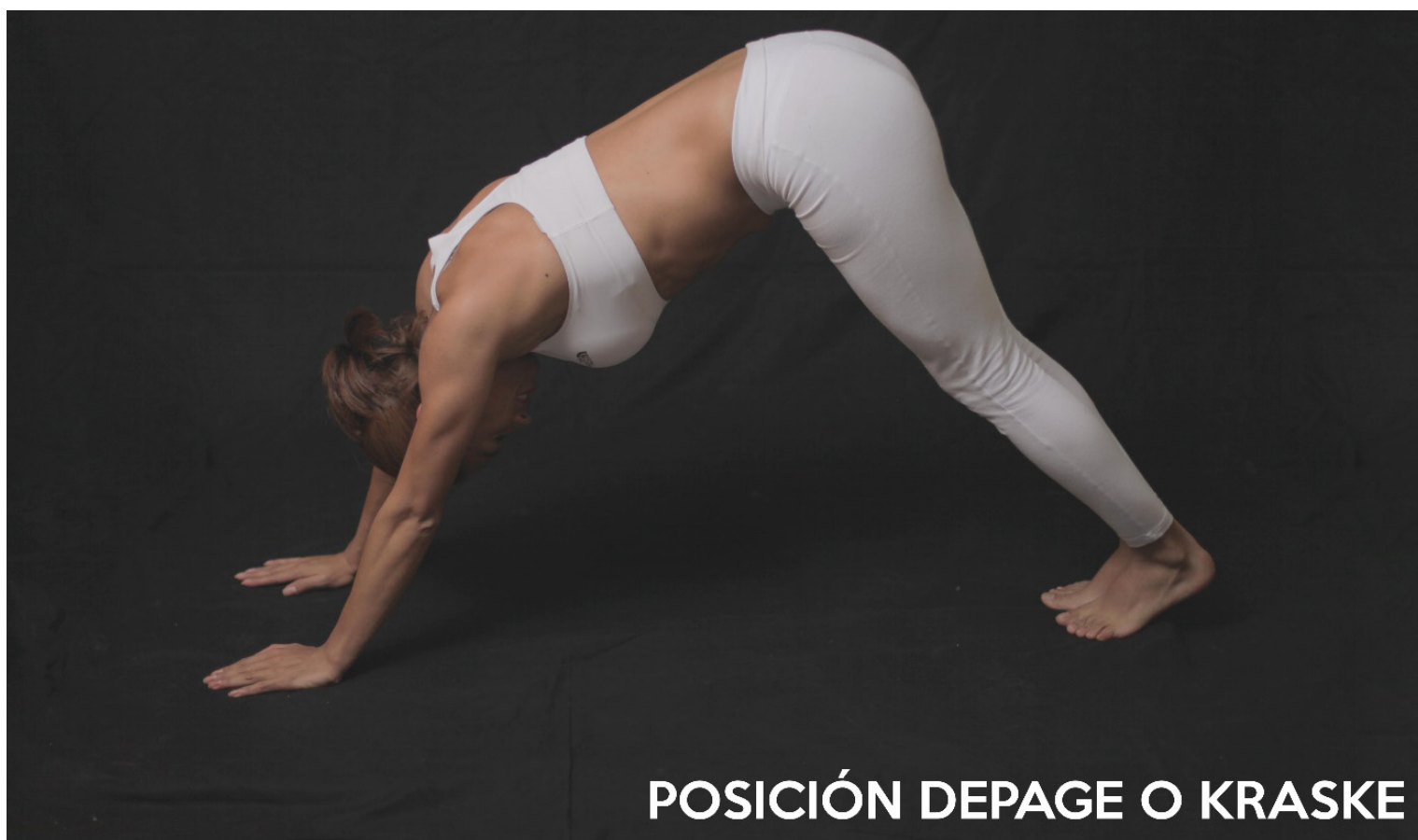

Figura Nro. 37 


\section{POSICIÓN DE LAS EXTREMIDADES}

- BRAZOS EN EXTENSIÓN: es cuando una o ambas manos están alejadas del tronco del cuerpo (ver figura Nro. 38).

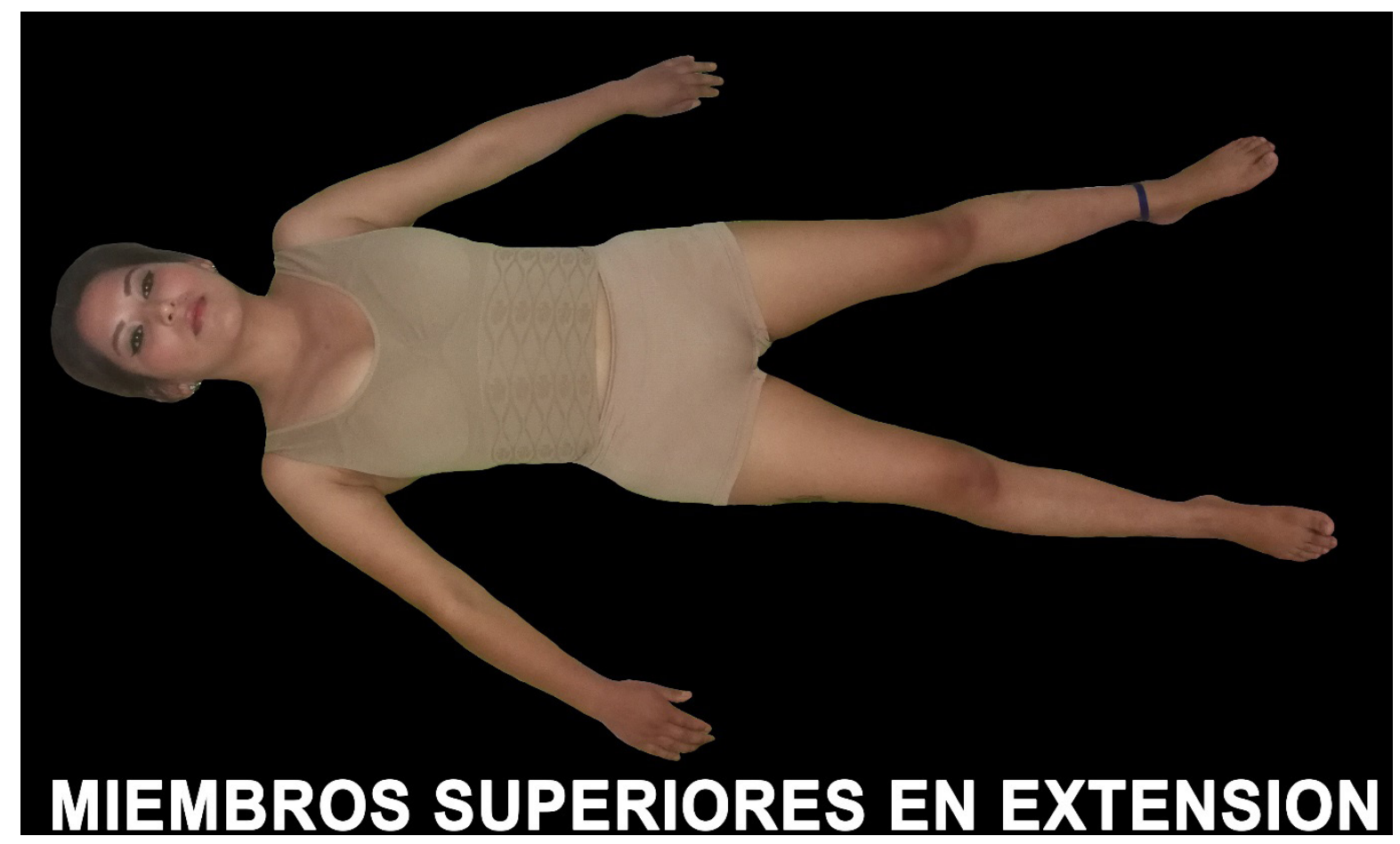

Figura Nro. 38

- BRAZOS EN ADUCCIÓN: una o ambas manos están cerca o pegadas al tronco del cuerpo (ver figura Nro. 39).

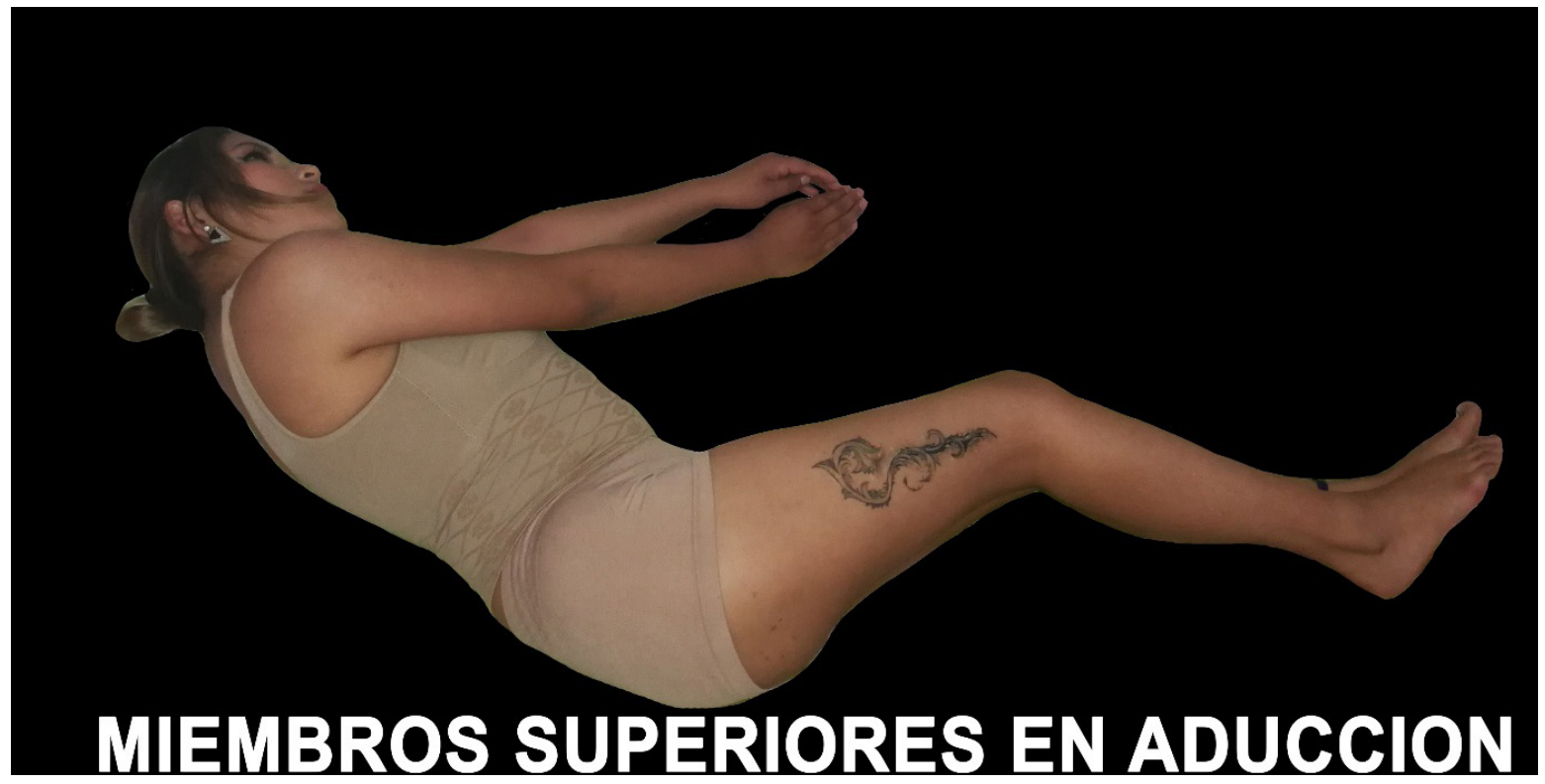

Figura Nro. 39

- BRAZOS EN FLEXIÓN: Una o ambas extremidades están flexionadas, es importante definir que extremidad es la que se encuentra en flexión (ver figura 


\section{Revista Científica de Salud UNITEPC}

Nro. 40).

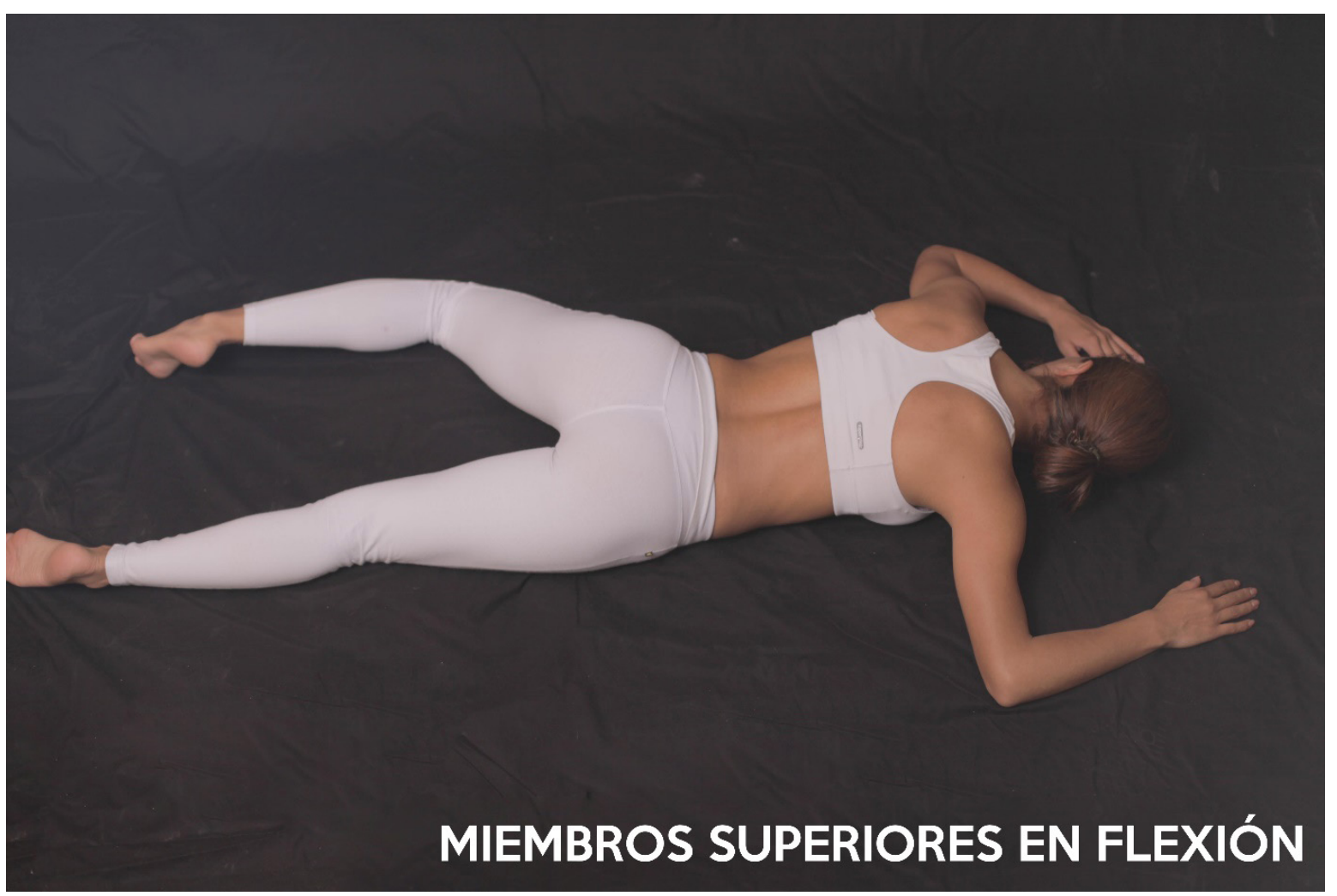

Figura Nro. 40

- PIERNAS EN EXTENSIÓN: A diferencia de las manos, las piernas se consideran en extensión cuando están completamente estiradas (ver figura Nro. 41).

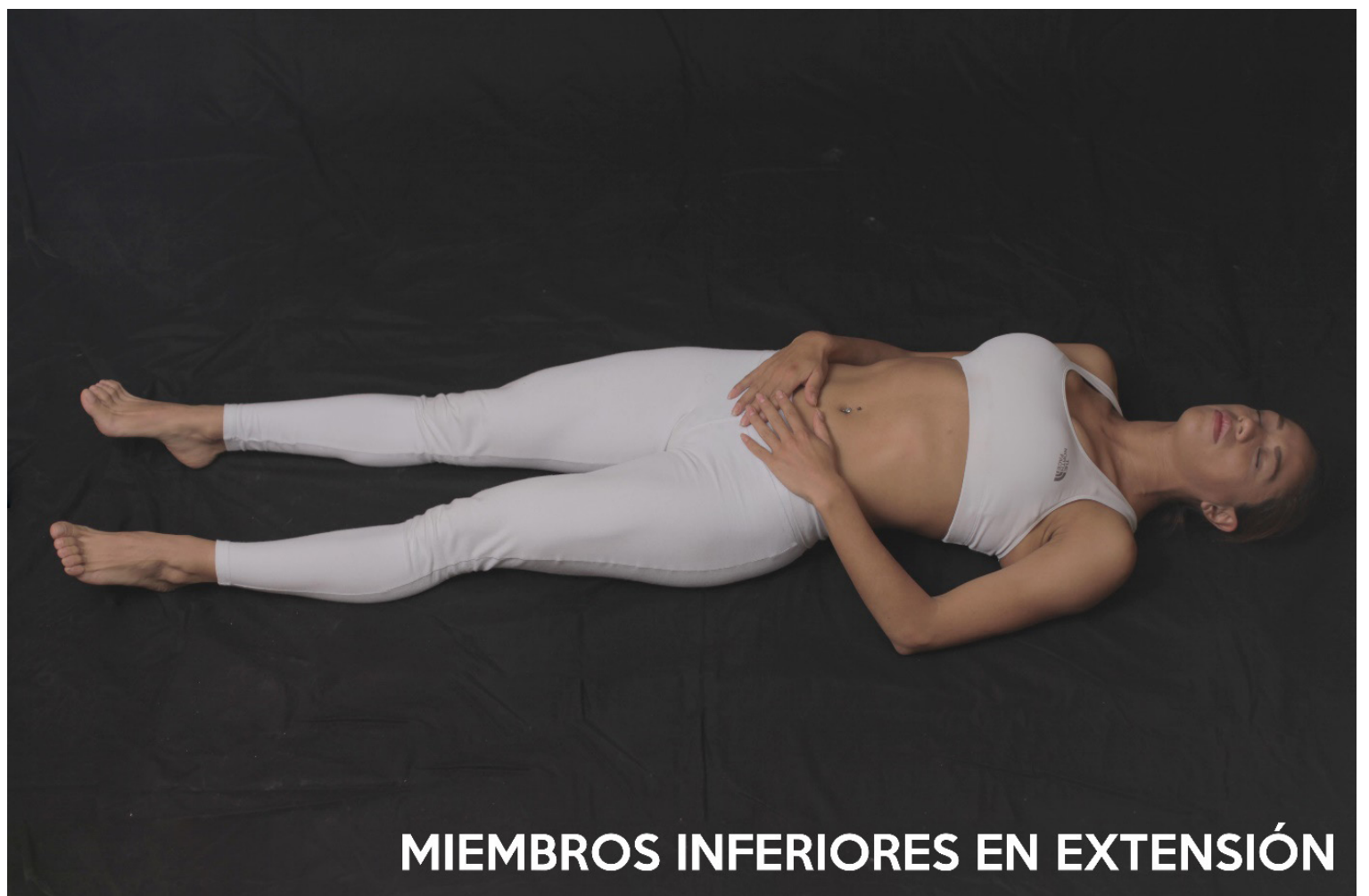

Figura Nro. 41 
- PIERNAS EN ABDUCCIÓN: Es cuando las piernas están en ángulo máximo de 45 grados se consideran en aducción (ver figura Nro. 42).

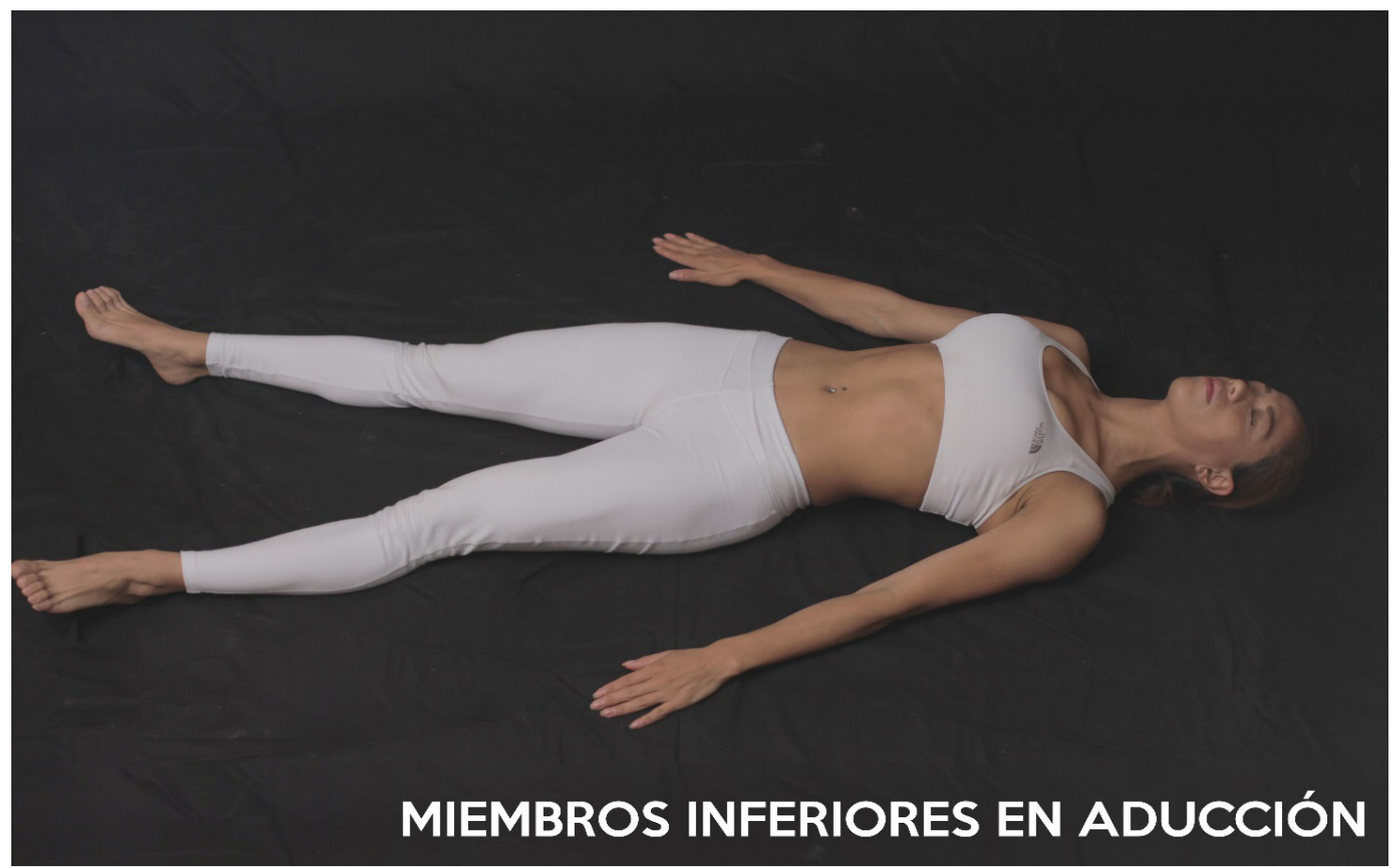

Figura Nro. 42

- PIERNAS EN FLEXIÓN: Es importante tomar nota cuál de las dos piernas es la que está en flexión en el caso de violación es común que ambas piernas presenten esta posición (ver figura Nro. 43).

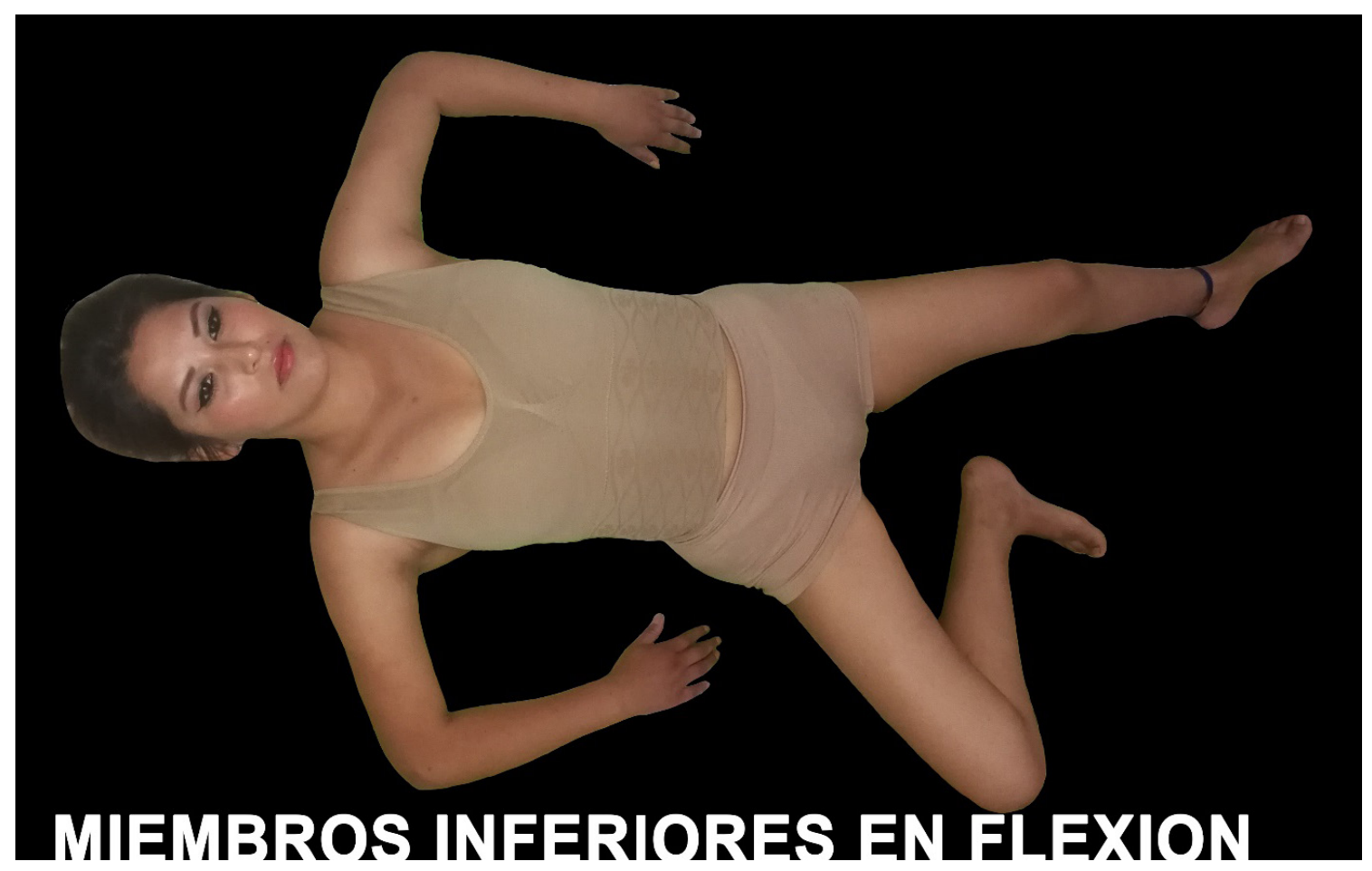

Figura Nro. 43 


\section{Revista Científica de Salud UNITEPC}

- EXTREMIDADES EN ROTACIÓN: Es el movimiento sobre un eje, se habla de rotación interna cuando el giro se da hacia el mismo cuerpo, y externa cuando el giro coloca el miembro apuntando hacia afuera del cuerpo (ver figura Nro. 44).

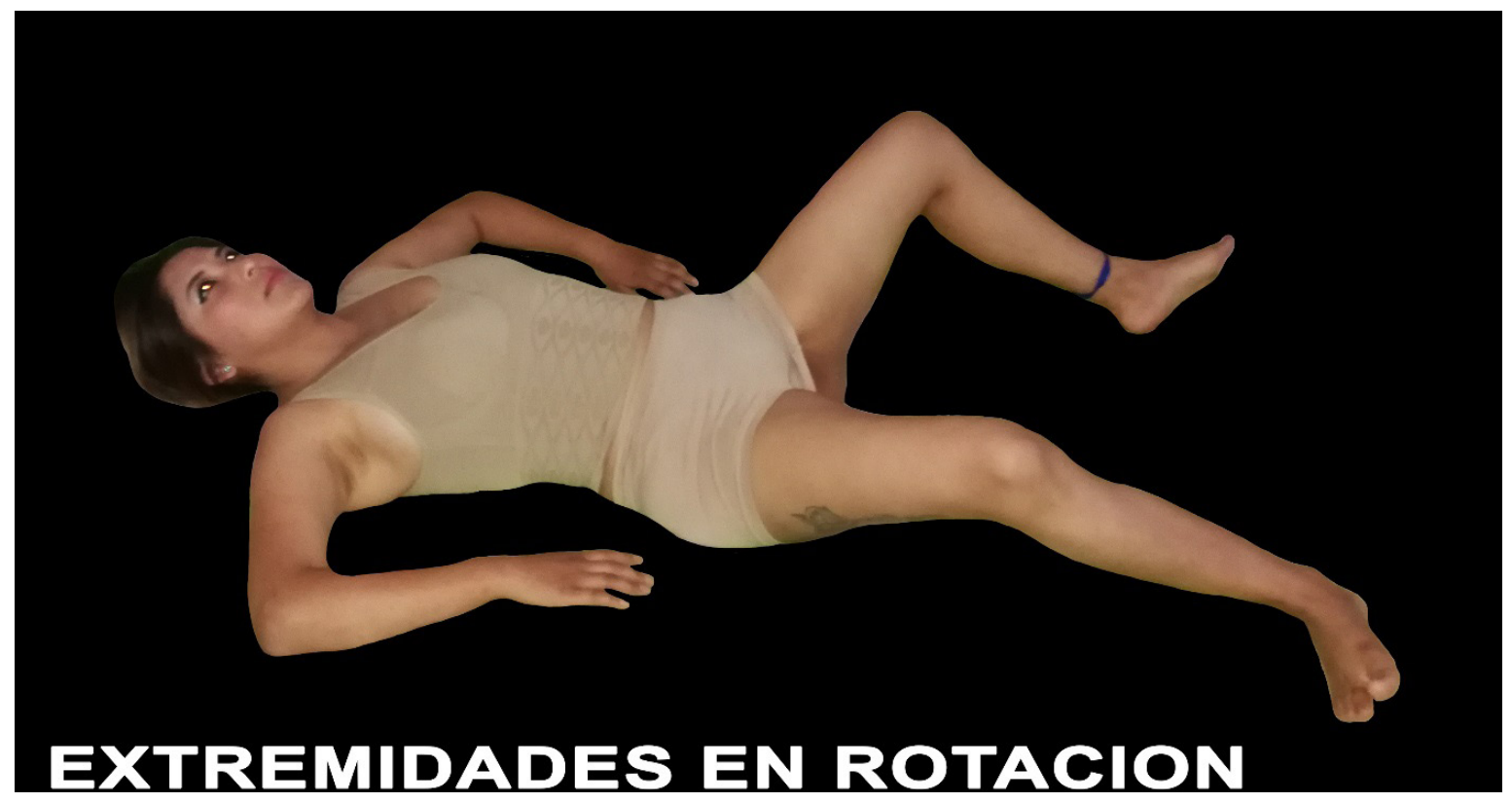

Figura Nro. 44

\section{POSIBLES MANERAS DE MUERTE SEGÚN POSICIÓN CADAVÉRICA}

\begin{tabular}{|c|c|c|}
\hline $\begin{array}{l}\text { POSICIÓN DEL } \\
\text { CUERPO }\end{array}$ & $\begin{array}{c}\text { ETIOLOGÍA MÉDICO LE- } \\
\text { GAL }\end{array}$ & DELITO SEGÚN CP \\
\hline Decúbito dorsal o supino & $\begin{array}{l}\text { Homicidios, accidentales } \\
\text { (caídas, precipitaciones, } \\
\text { hechos de tránsito), }\end{array}$ & $\begin{array}{l}\text { Arts. } 251 \text { (sus } \\
\text { agravantes y ate- } \\
\text { nuantes), } 270 \text { (sus } \\
\text { agravantes y ate- } \\
\text { nuantes). }\end{array}$ \\
\hline Decúbito ventral o prono & $\begin{array}{l}\text { Homicidios, accidentales } \\
\text { (caídas, precipitaciones, } \\
\text { hechos de transito), }\end{array}$ & $\begin{array}{l}\text { Arts. } 251 \text { (sus } \\
\text { agravantes y ate- } \\
\text { nuantes), } 270 \text { (sus } \\
\text { agravantes y ate- } \\
\text { nuantes). }\end{array}$ \\
\hline Decúbito lateral Derecho & $\begin{array}{l}\text { Homicidios, accidentales } \\
\text { (caídas, precipitaciones, } \\
\text { hechos de tránsito), }\end{array}$ & $\begin{array}{l}\text { Arts. } 251 \text { (sus } \\
\text { agravantes y ate- } \\
\text { nuantes), } 270 \text { (sus } \\
\text { agravantes y ate- } \\
\text { nuantes). }\end{array}$ \\
\hline
\end{tabular}




Decúbito lateral Izquierdo
Posición sedente

Suspensión completa:

Suspensión incompleta

Sumersión completa

Sumersión incompleta

Posición del boxeador

Posición fetal

Tónico-Cervical Asimétri- Accidentales, homicidios co (Esgrimista)

Roser o Proetz

Posición Genu/pectoral
Suicidios, homicidios

homicidio

Homicidios, accidentales (caídas, precipitaciones, hechos de tránsito),

Homicidios, suicidios

Suicidios, homicidios

Accidentales, suicidios, homicidios

Accidentales, suicidios, homicidios

Accidentales, homicidios.

Homicidio, suicidio

Violaciones, manos atadas.
Arts. 251 (sus

agravantes y atenuantes), 270 (sus agravantes y atenuantes).

Arts. 251 (sus agravantes y atenuantes), en especial art.256.

Arts. 251 (sus agravantes y atenuantes), en especial art.256.

Arts. 251 (sus agravantes y atenuantes), en especial art.256.

Arts. 251 (sus agravantes y atenuantes), en especial art.256.

Arts. 251 (sus agravantes y atenuantes), en especial art.256.

Arts. 251 (sus agravantes y atenuantes).

Arts. 251 (sus agravantes y atenuantes).

Arts. 251 (sus agravantes y atenuantes).

Arts. 251 (sus agravantes y atenuantes), en especial art.256.

Arts. 251 (sus agravantes y atenuantes), 308 y sus agravantes y atenuantes. 


\section{CONCLUSIÓN.}

a. El levantamiento de cadáveres de la escena consiste en un estudio detallado minucioso o metódico de todas las pruebas médico legales, realizadas en el lugar del hecho. Por ello la importancia de entender que la tarea no consiste únicamente en realizar el levantamiento y transporte de la víctima, pues existen tareas complementarias que realizar en el sitio como ser: Exploración del lugar del hecho (armas, cartas, documentos, manchas, cuerdas, etc.), exploración de las vestimentas (prendas, perforaciones, desgarros, pertenencias, etc.), y exploración externa del cadáver (actitud, posición).

b. Existen diferentes tipos de posiciones cadavéricas importantes dentro de una escena del hecho, que pueden ser calificadas en tres hipótesis, que el sujeto pasivo haya sufrido un homicidio, que el sujeto pasivo se haya suicidado, o que el sujeto pasivo ha sufrido un accidente ya sea por descuido o provocado por algún tercero.

c. También cobra importancia al momento de determinar si el cadáver fue movido de su posición original o del lugar del hecho.

d. Hay posiciones cadavéricas que son comunes para el homicidio como son el decúbito dorsal y ventral; para el suicidio, la suspensión completa e incompleta, etc. pero esto no quiere decir que no se puedan dar en otros casos distintos

e. Una buena descripción de la posición cadavérica orientara al perito, investigador asignado, policías, etc. de cómo sucedieron los hechos y a determinar la manera de muerte.

\section{REFERENCIAS BIBLIOGRÁFICAS}

1. Montiel Sosa, Juventino, Criminalística, Instituto de Formación Profesional, Procuraduría General de Justicia del Distrito Federal, México, 1978.

2. Simonin, Camilo, Medicina legal Judicial, JIMS, Barcelona Espana, 1972

3. Villavicencio Ayala, Miguel José, Procedimientos de investigación Criminal, Limusa, México, 1974

4. Simonin, Camilo, Medicina legal judicial, JIMS, Barcelona, España, 1972, pg 207.

5. Simonin, Camilo, Medicina legal judicial, JIMS, Barcelona, España, 1972, pg 208.

6. Medicina Legal de Costa Rica, vol. 27 (2), setiembre 2010. ISSN 1409-0015.

7. Soderman, Harry y John J. O’Connell, Métodos modernos de investigación policiaca, Limusa, México, 1972.

8. Patitó, J. (2003). Tratado de Medicina Legal y Elementos de Patología Forense. Ciudad Autónoma de Buenos Aires, Argentina: Editorial Quorum

9. Roldán, J., \& Solano, L. Departamento de Medicina Legal. Organismo de Investigación Judicial. Poder Judicial. Medicina Legal de Costa Rica, 2001, pg.18.

10. Palomo, J., \& Ramos, V. Papel del Médico Forense en la Inspección Ocular y Levantamiento del Cadáver. Cuadernos de Medicina Forense, 2004, pg. 36, 41-57

11. Guía médico legal, evaluación física de la integridad sexual, segunda versión lima Perú, pg.40

12. Guía médico legal, evaluación física de la integridad sexual, segunda versión lima 
Perú; pág. 68.

13. Ugalde, J. El Derecho a la Autopsia Médico Legal: el caso del privado de libertad. Revista Latinoamericana de Derecho Médico y Medicina Legal, 1998-1999, pg. 33-38.

14. Castillo, M. Manejo del Cadáver en la Escena del Crimen. Tesis de Grado. Universidad Rafael Landivar. Guatemala 2014, pg 15.

15. Gonzales, J Practica forense en Derecho Penal. Documento. Universidad Nacional Autónoma de México. 2015, pg 8.

16. Curso de Investigación del delito y Aplicaciones Forenses "Tanatología Forense" Dr. Wilmer Atilio Segura Vílchez Médico Legista, Anatomopatólogo, Médico Auditor, Maestría en Salud Pública. Escuela del Ministerio Publico - Lima

17. Solano, G. Manejo del Escenario de Muerte y Autopsia Médico Legal, revisión bibliográfica, Costa Rica 2010 Pag. 47-58 